\title{
EVALUATION OF OPTIMUM CONFIGURATIONS FOR COMPOSITE OILFIELD THREE-PHASE SEPARATOR PRESSURE VESSEL
}

\author{
A. A. Hassan', M. Abo-Elkhier', B. Abd El-bary ${ }^{3}$ \\ ${ }^{1}$ Piping stress analysis engineer, Engineering for the Petroleum \& \\ Process Industries Company - ENPPI, Cairo, Egypt (corresponding \\ author, phone: 202-227-62137 - Ext: 3584; fax: 202-227-44382, \\ e-mail: ahmed.abdelfattah@enppi.com). \\ ${ }^{2}$ Professor, Menoufia University, Faculty of Engineering, Production \\ Engineering \& Mechanical Design Department, Egypt, \\ (e-mail: mahmoudaboelkhier@hotmail.com). \\ ${ }^{3}$ Assistant Professor, Menoufia University, Faculty of Engineering, \\ Production Engineering \& Mechanical Design Department, Egypt, \\ (e-mail: badrelbary16@gmail.com).
}

\begin{abstract}
:
Gravity three-phase separators consist of pressure vessel with multiple internals that utilize gravity settlement to separate gas/water/oil free from each other. The pressure vessel represents the substantial element of such separators. Limited work has been reported on investigating fluid contained multilayered filament-wound composite pressure vessels. However, destructive testing with full scale or subscale is the best method to determine the structural characteristics of filamentwound pressure vessels as it requires an excessive cost. In this study, three parametric numerical models have been undertaken to represent three load cases namely; pure pressure, operating, and hydro-test load cases in order to predict optimum lay-up for filament-wound pressure vessels of sglass/epoxy, carbon/epoxy composite laminates and hybrid of both for certain configurations. ANSYS (ACP) 17.0 commercial software was used for simulation and analysis. ANSYS Workbench design point parameters were used to construct parametric models. A developed mathematical solution used from cited work was employed for results verification using Tsai-Wu failure criterion for the safe design assessment in terms of safety factor. The findings indicate that for operating load case, optimum lay-up should be selected according to foreseen loading ratio acting upon pressure vessel during its lifetime, and hydro-test load case is safe for all studied layups also.

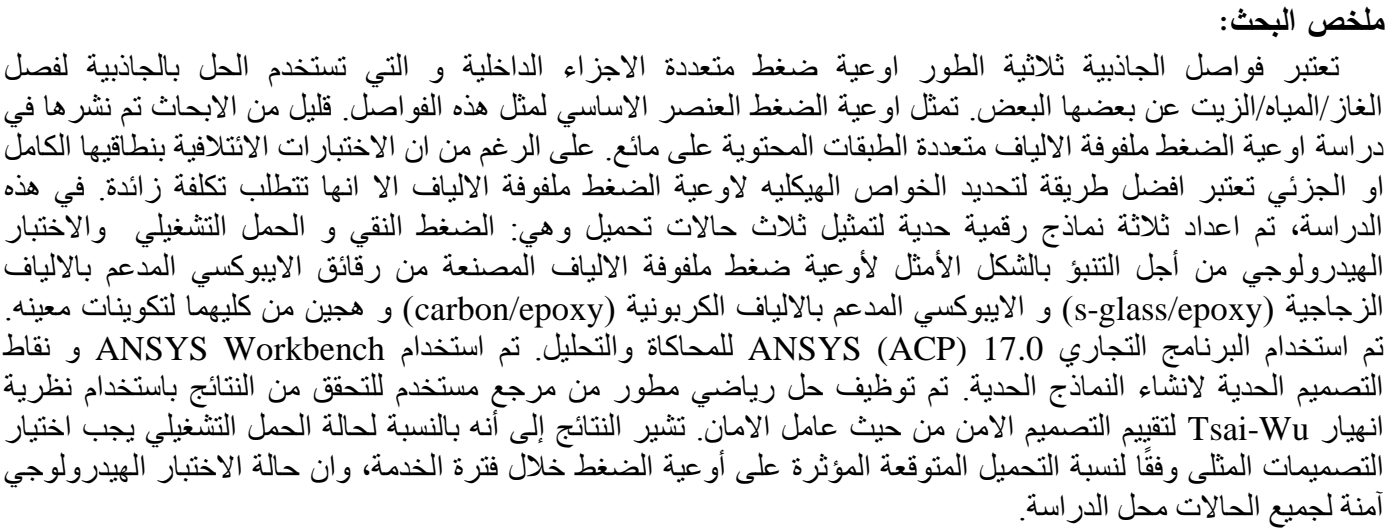

Keywords: ANSYS, Filament winding, Finite element analysis, Modeling and simulation, Pressure vessel, Three-phase separator. 


\section{INTRODUCTION}

Phase separators are deemed to be one of the most significant inlet facilities for gas processing plants. Well-head stream contains mixed gaseous and liquid components that should be segregated as a part of initial processing for natural gas [1]. Three principles are utilized for phase separation purpose namely; coalescing, momentum and gravity settlement. Gravity separators are simply pressure vessels used for mixed phase well stream separation into gas and fluids. Three-phase horizontal separators are ordinarily used to separate oil/gas/water relatively free of each other as shown in Fig. 1.

Composite tubular containers are widely used in piping systems and storage containers exist in chemical industries and processing plants [2], [3].

Owing to their distinct mechanical characteristics such as: high corrosion resistance, and lightweight attributes. Filament winding is the most common fabrication technique for axisymmetric polymer matrix composite cylindrical structures [4]. It can be divided into two different types: dry winding, in which prepregs are utilized and wet winding, in which filaments are impregnated in a resin bath. In wet winding, reinforcement is applied through an inline traveling carriage on a rotating mandrel. Relative movement between carriage and mandrel is adjusted to obtain the required winding angle. Resultant structural properties are customized mainly based on winding pattern; helical, hoop and polar or hybrid stacking using different patterns [5].

\section{NOMENCLATURE}

\begin{tabular}{|c|c|c|}
\hline Symbol & Description & Units \\
\hline $\mathbf{D}_{\mathbf{i}}$ & $\begin{array}{l}\text { Internal diameter of pressure } \\
\text { vessel }\end{array}$ & $\mathrm{mm}$ \\
\hline $\mathbf{D}_{\mathbf{o}}$ & $\begin{array}{l}\text { Outer diameter of pressure } \\
\text { vessel }\end{array}$ & $\mathrm{mm}$ \\
\hline $\mathbf{E}_{1}$ & Longitudinal tensile modulus & $\mathrm{MPa}$ \\
\hline $\mathbf{E}_{2}$ & Transverse tensile modulus & $\mathrm{MPa}$ \\
\hline FEA & Finite element analysis & - \\
\hline FEM & Finite element modeling & - \\
\hline $\mathbf{F}_{\mathbf{a}}$ & Pseudo-axial thrust force & $\mathrm{N}$ \\
\hline $\mathbf{F}_{\mathrm{s}}$ & $\begin{array}{l}\text { Torsional force due to nozzle } \\
\text { load }\end{array}$ & $\mathrm{N}$ \\
\hline $\mathbf{F}_{1 \mathrm{c}}$ & $\begin{array}{l}\text { Longitudinal compressive } \\
\text { strength }\end{array}$ & $\mathrm{MPa}$ \\
\hline $\mathbf{F}_{1 \mathrm{t}}$ & Longitudinal tensile strength & $\mathrm{MPa}$ \\
\hline $\mathbf{F}_{2 c}$ & $\begin{array}{l}\text { Transverse } \quad \text { compressive } \\
\text { strength }\end{array}$ & $\mathrm{MPa}$ \\
\hline $\mathbf{F}_{2 t}$ & Transverse tensile strength & $\mathrm{MPa}$ \\
\hline $\mathbf{F}_{6}$ & In-plane shear strength & $\mathrm{MPa}$ \\
\hline $\mathbf{G}_{12}$ & In-plane shear modulus & $\mathrm{MPa}$ \\
\hline
\end{tabular}

\begin{tabular}{|c|c|c|}
\hline H:A & Hoop to axial load ratio & - \\
\hline $\mathbf{h}$ & Thickness of pressure vessel & $\mathrm{mm}$ \\
\hline $\mathbf{h}_{\mathbf{a}}$ & $\begin{array}{l}\text { Allowable thickness of pressure } \\
\text { vessel }\end{array}$ & $\mathrm{mm}$ \\
\hline $\mathbf{L}$ & Pressure vessel length & $\mathrm{mm}$ \\
\hline $\mathbf{L}_{\mathrm{s}}$ & Span length between saddles & $\mathrm{mm}$ \\
\hline L/D & Pressure vessel aspect ratio & - \\
\hline $\mathbf{n}$ & Number of basic laminates & - \\
\hline $\mathbf{N}_{\mathrm{s}}$ & Shear force per unit length & $\mathrm{N} / \mathrm{mm}$ \\
\hline $\mathbf{N}_{\mathbf{x}}$ & $\begin{array}{l}\text { Axial thrust force per unit } \\
\text { length }\end{array}$ & $\mathrm{N} / \mathrm{mm}$ \\
\hline $\mathbf{P}_{\text {hyd }}$ & Hydro-test pressure & $\mathrm{MPa}$ \\
\hline $\mathbf{P}_{\mathbf{i}}$ & Internal design pressure & $\mathrm{MPa}$ \\
\hline $\mathbf{R F}$ & Reserve factor & - \\
\hline $\mathbf{r}_{\mathbf{i}}$ & $\begin{array}{l}\text { Internal radius of pressure } \\
\text { vessel }\end{array}$ & $\mathrm{mm}$ \\
\hline $\mathbf{r}_{\mathbf{m}}$ & Mean radius of pressure vessel & $\mathrm{mm}$ \\
\hline $\mathbf{r}_{\mathbf{o}}$ & Outer radius of pressure vessel & $\mathrm{mm}$ \\
\hline $\mathbf{S}_{\text {fall }}$ & Allowable safety factor & - \\
\hline $\mathbf{S}_{\mathrm{fH}}$ & Hydro-test safety factor & - \\
\hline $\mathbf{S}_{\mathrm{fH} 0}$ & $\begin{array}{l}\text { Hydro-test safety factor at zero } \\
\text { span }\end{array}$ & - \\
\hline $\mathbf{T}$ & $\begin{array}{l}\text { Applied torque due to } \\
\text { attachment }\end{array}$ & N.mm \\
\hline $\mathbf{t}$ & Ply thickness & $\mathrm{mm}$ \\
\hline VBA & Visual basic for applications & - \\
\hline
\end{tabular}

Mandrel materials are chosen according to their end condition, metallic mandrels are used for open-ended type, and disposable water-soluble salts for closed- 
ended pressure vessel like [6]. Moreover, polymer or metallic mandrels may be left inside a filamentwound pressure vessel as a liner [7].

With the rapid growth of modern composite structures, theoretical, and numerical analyses of such structures are gaining great importance to scientists and designers. Defining precise computational and numerical models could save analyses time. Thin pressure vessels are threedimensional bodies in nature with a considerably smaller dimension. The thickness is smaller than the other two dimensions, that directly lead to the use of reduced economical two-dimensional in lieu of complex, costly three-dimensional analysis [8].

Various studies were carried out for the response optimization of filament-wound pressure vessels exposed to particular loading conditions. Winding angle is considered as one of the most significant design aspects. Rosenow [9] carried out an experimental investigation for composite glassreinforced plastic pipes exposed to pure axial, hoop loading, and biaxial pressure loading conditions. Classical lamination theory was utilized to predict the optimum wind angle that was found at $54.75^{\circ}$. This is in conformance with the results obtained from a simple technique called netting analysis. The netting analysis technique considers that fibers are only exposed to load underestimating the effect of matrix load sharing ability [10].

Onder et al. [11] introduced a mathematical solution and finite element model using ANSYS 10.0

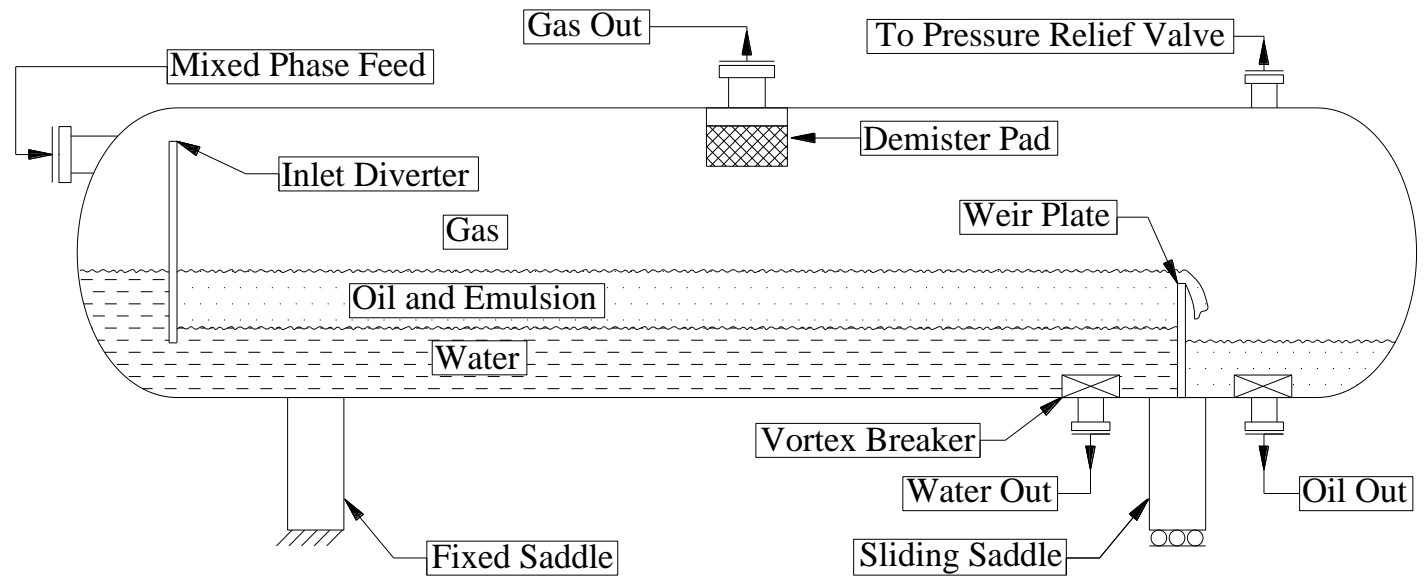

Fig. 1 Horizontal oilfield three-phase separator schematic

to investigate the impact of winding angle of internally pressurized composite cylinders with closed-ended boundary condition, pressure vessel like, upon the value of burst pressure. They conducted an experimental study to investigate the optimum winding angle for both symmetric and antisymmetric configurations. The optimum winding angle was obtained at $55^{\circ}$. The developed analytical solution showed a good correspondence with experimental results for most orientations. Furthermore, the FEM gives good agreement for some orientations.

Sayman et al. [12] examined experimentally the burst pressure of a closed-ended E-glass/epoxy composite pipe $100 \mathrm{~mm}$ diameter under internal pressure. Four anti-symmetric configurations were studied. The highest failure pressure was obtained at $55^{\circ}$. The failure of first ply was found to be inversely proportional to the temperature owing to low strength of the composite materials and higher thermal stresses at high temperatures.

Martins et al. [13] investigated the structural and functional failure through numerical and experimental studies. An alternative damage model using the user subroutine (UMAT) in ABAQUS commercial software was proposed for performing the progressive damage modeling. Four closed-ended internally pressurized tubes with the following lay-up configurations: $\left[ \pm 45^{\circ}\right]_{4},\left[ \pm 55^{\circ}\right]_{4},\left[ \pm 60^{\circ}\right]_{4}$ and $\left[ \pm 75^{\circ}\right]_{4}$ were studied. The maximum functional and structural failure pressure was found to be $4.95 \mathrm{MPa}$ for the second configuration.

Parnas and Katirci [14] developed a mathematical solution using classical laminated plate theory to predict the structural response of a pressure vessel using two approaches based upon the wall thickness. They investigated the burst pressure of pressure vessels exposed to various loading conditions. Xia et al. [15] derived an exact solution to determine stresses and deformations within filament-wound pressure vessel under internal pressure only, based on three-dimensional (3D) anisotropic elasticity.

Towards minimizing costs of experimental determination of structural behavior, sub-scale studies were gaining more importance. Martins et al. [16] conducted a study to identify the minimum sufficient length that represent experimentally pressure vessel exposed to hydrostatic test. They found that the aspect ratio of length over diameter, $\mathrm{L} / \mathrm{D}=11$ was sufficient to represent the infinite length without significant error. 
Shao et al. [17] studied experimentally the effect of matrix material upon the burst pressure of filament wounded pressure vessel with an aluminum liner. Using the same content of carbon fiber with vinylester and epoxy matrix with [90/ \pm 15$]$ layup configuration, the vinylester matrix based pressure vessel showed higher load carrying capacity which resulted in a burst pressure 20\% higher than epoxy matrix based one.

Perillo et al. [18] introduced a (3D) damage model to simulate the impact events over a filament wound composite pressure vessel employing ABAQUS commercial FE software. Hashin failure criteria was employed for investigating failure of fiber and, the Puck criterion was used for matrix cracks prediction. The proposed FE model predicted the impact curves precisely comparing with the experimental work undergone in the same work.

Kamal et al. [19] proposed a mathematical solution and finite element model to identify weight saving can be achieved using composite versus stainless steel pressure vessel under pure pressure only. Four diameter size vessels were used; E-glass/epoxy, carbon/epoxy (AS4/3501-6) and hybrid of both were employed for five layup configurations. The optimum angles were obtained at $55^{\circ}$, and $54^{\circ}$ for carbon/ epoxy, and E-glass/epoxy respectively, and [90G/ $\pm 50 \mathrm{C} / 90 \mathrm{G}]$ for hybrid one. The major drawback of their work is that both solutions assumed that pressure vessel is exposed only to pure pressure neglecting the effect of pressure vessel selfweight and its contents and/or any external loads. This could be acceptable for small bore pressure vessels, but not valid for large bore because the weight of fluid contained vessel is very large comparable to the weight of empty vessel as shown in Fig. 2.

Furthermore, choosing four different diameter sizes may be not enough to elaborate to study the effect of the stress ratio upon the optimum winding angle. In a recent publication [20], they have performed an experimental, analytical and FEM investigation for the failure pressure of closed-ended and open-ended E-glass/polyester pipes. The analytical results showed good agreement with the experimental output. Meanwhile the FEM results showed more precise results.

This research aims to determine the safe design for a filament-wound composite pressure vessel under more realistic load cases that was not considered in previous mentioned studies. Operating and hydro-test load cases were introduced using developed mathematical and numerical models. Minimum allowable structural thickness was determined based on the dominant load which is the internal design pressure, which determine the change in safety factor when introducing the other load cases. The composite materials utilized for constructing pressure vessel were; S-glass/epoxy, carbon/epoxy and hybrid of both accompanied with selected five symmetric laminate lay-ups.

\section{PROBLEM STATEMENT}

First stage three-phase separator belongs to $\mathrm{Abu}$ Dhabi Company for onshore oil operations (ADCO) was sized using process simulation, based on the mixed-phase feed analysis data [21]. An alternative composite multilayered filament-wound pressure vessel was proposed. Upset design pressure was considered to be $2 \mathrm{MPa}$ with a safety margin of approximately $16 \%$ above the operating pressure. This can be practically achieved using a safety valve to maintain pressure at certain value. The effect of inclusion of design pressure associated with torsional force due to external attachment like nozzle, and hydro-test considering the self-weight and fluid contained weight are investigated using numerical models. Parametric models are constructed using finite element modeling. The results are validated using data obtained from mathematical solution introduced in previous work [19] for pure pressure load case and developed solution for operating load case. Parametric models were constructed to determine the effect upon the design safety for both operating and hydro-test load cases. Operating and installation temperatures were considered to be equal to the ambient temperature, so that the thermal effects can be conceivable ignored.

\section{MATHEMATICAL MODELING}

Previous research has studied mathematically filament wounded pressure vessels subjected to internal pure pressure [19]. In this investigation, a mathematical model based on classical lamination theory, laminates lay-ups, fiber orientation, and layers coordinate notation used in reference [19] was employed for both pure pressure and operating load cases. Two types of unidirectional composite materials are used namely; S-glass/epoxy and carbon/epoxy (IM6/SC1081), their properties are indicated in Table I [22].

Tsai-Wu failure criteria [23] were introduced to evaluate the safety factor for every lay-up. The whole solving procedure was done using a Microsoft Excel VBA-Macro. The layer winding angle was studied ranging from $0^{\circ}$ to $90^{\circ}$ with a step size of $0.1^{\circ}$ and the corresponding allowable structural thickness was determined. Macro then calculated the minimum allowable thickness achieving safety factor value of $\left(\mathrm{S}_{\text {fall }}=2\right)$ based on Tsai-Wu failure criteria. Assuming a ply thickness $\mathrm{t}=0.5 \mathrm{~mm}$, the conceptual sizing for structural wall thickness was calculated under pure internal operating pressure of $2 \mathrm{MPa}$.

For studying operating load case in which internal design pressure and external torsional effect due to external attachment introduced. A supplementary Macro was utilized when applying torsional force, $S_{f}$ 
represented output. The same mathematical formulation was used for introducing the shear force per unit length component $\mathrm{N}_{\mathrm{s}}$, if the average shear stress is $\left(\tau_{\mathrm{s}}\right)_{\text {average. }}$ The applied torque $\mathrm{T}$ is then given by [5]:

$$
T=\left(\tau_{s}\right)_{\text {average }} \pi\left(r_{o}^{2}-r_{i}^{2}\right) r_{m}
$$

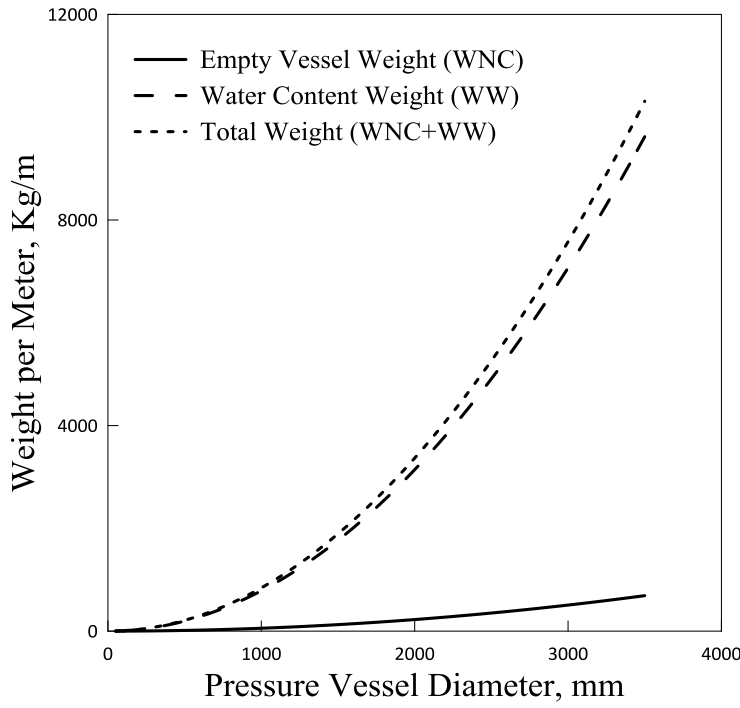

Fig. 2 Alteration of weight per meter versus filament-wound pressure vessel diameter

\section{Table I PROPERTIES OF COMPOSITE MATERIALS}

\begin{tabular}{lcc}
\hline \hline \multicolumn{1}{c}{ Properties } & S-glass/Epoxy & $\begin{array}{c}\text { Carbon/Epoxy } \\
\text { (IM6/SC1081) }\end{array}$ \\
\hline \hline Fiber volume fraction, $\mathrm{V}_{\mathrm{f}}$ & 0.5 & 0.65 \\
Density, $\rho, \mathrm{kg} / \mathrm{m}^{3}$ & 2 & 1.6 \\
Longitudinal modulus, $\mathrm{E}_{1}, \mathrm{GPa}$ & 43 & 177 \\
Transverse modulus, $\mathrm{E}_{2}, \mathrm{GPa}$ & 8.9 & 10.8 \\
In-plane shear modulus, $\mathrm{G}_{12}, \mathrm{GPa}$ & 4.5 & 7.6 \\
Major Poisson's ratio, $v_{12}$ & 0.27 & 0.27 \\
Minor Poisson's ratio, $v_{21}$ & 0.06 & 0.02 \\
Longitudinal tensile strength, $\mathrm{F}_{1 \mathrm{t}}, \mathrm{MPa}$ & 1280 & 2860 \\
Transverse tensile strength, $\mathrm{F}_{2 \mathrm{t}}, \mathrm{MPa}$ & 49 & 49 \\
In-plane shear strength, $\mathrm{F}_{6}, \mathrm{MPa}$ & 69 & 83 \\
Ultimate longitudinal tensile strain, $\epsilon_{1 \mathrm{t}}$ & 0.029 & 0.016 \\
Ultimate transverse tensile strain, $\epsilon_{2 \mathrm{t}}$ & 0.006 & 0.005 \\
Longitudinal compressive strength, $\mathrm{F}_{1 \mathrm{c}}, \mathrm{MPa}$ & 690 & 1875 \\
Transverse compressive strength, $\mathrm{F}_{2 \mathrm{c}}, \mathrm{MPa}$ & 158 & 246 \\
\hline \hline
\end{tabular}

Where,

$r_{0} \quad$ is the outer radius of pressure vessel in $\mathrm{mm}$ $r_{i} \quad$ is the inner radius of pressure vessel in $\mathrm{mm}$ $r_{m} \quad$ is the mean radius of pressure vessel in $\mathrm{mm}$ The mean radius can be determined as follows:

$$
r_{m}=\frac{r_{o}+r_{i}}{2}
$$

And pressure vessel thickness, $\mathrm{h}$ was expressed as:

$$
h=r_{o}-r_{i}
$$

The shear force per unit length is given by:

$$
N_{s}=\left(\tau_{s}\right)_{\text {average }} h
$$

The applied torque can be expressed also in terms of the torsional force $\mathrm{F}_{\mathrm{s}}$ as follows:

$$
T=F_{s} r_{m}
$$

Using (1) to (5) thus:

$$
N_{s}=\frac{T}{2 \pi r_{m}^{2}}=\frac{F_{s}}{2 \pi r_{m}}
$$

For simplicity the shear force per unit length, $\mathrm{N}_{\mathrm{s}}$ is implemented in mechanical loading matrix as a ratio of the axial thrust force per unit length, $\mathrm{N}_{\mathrm{x}}$ due to internal pressure as such that $\mathrm{N}_{\mathrm{s}} / \mathrm{N}_{\mathrm{x}}=0$ to 5 (with a step size of 0.1 ). The detail of the mathematical 
model is fully described in previous work [19] ; therefore, major changes are only outlined here.

The current mathematical model in use is valid only for plane stress load case so, hydro-test load case could not be simulated using such model. A more complicated expanded 3D model is needed which was not a scope of this study, so the hydro-test load case studied using validated numerical model constructed by finite element modeling only. Fig. 3 shows a visual representation of the load combination acting upon filament-wound pressure vessel and boundary conditions applied for the three studied load cases.

\section{FINITE ELEMENT ANALYSIS}

The finite element model was constructed for the composite filament-wound multilayered pressure vessel. Commercial software ANSYS Workbench 17.0 was used for the analysis employing ANSYS Composite PrepPost ${ }^{\mathrm{TM}}$ (ACP) [24] plugin for simulation of composite layers and analyzing failure criteria.

The pressure vessel was modeled as a continuous simply supported shell with two over hanged symmetric portions and a cross-section of a hollow cylinder with an inner diameter, $\mathrm{D}_{\mathrm{i}}$ of $3400 \mathrm{~mm}$. While, the outer diameter, $D_{0}$ get recognized based on the number of layers for every layup configuration, the span length between supports, $\mathrm{L}_{\mathrm{s}}$ $13600 \mathrm{~mm}$, and the over-hanged portions are only $1 / 12$ from the span length were modeled. For pure pressure load case, the influence of the end caps was modeled by means of applying two opposite pseudoaxial forces, $\mathrm{F}_{\mathrm{a}}$ at both ends of the pressure vessel to simulate the influence of end caps and achieve $2 \mathrm{H}$ : 1A loading condition [25]. On the other hand, for operating load case the same model used for pure pressure was developed adding parametric remote applied tangential force $F_{s}$ to simulate the effect of torsional force at mid-span neglecting PV, internals, and fluid content weights due to very low mixedphase feed density [21].

Applying Saint-Venant's Principle by replacing the torsional force by a statically equivalent system consisting of two pairs of coupling forces acting at the mid-span section to reduce the effect of applying a point load and get better safety factor distribution along the model [26], [27].

For hydro-test load case modeling, to simulate the fully filed PV, the same pure pressure model was modified through defining the PV weight and the internal content was defined as a cylinder of fluid inside the filament-wound PV model. Water was employed as a test fluid, and internal pressure of 1.5 times the operating pressure was applied. Fig. 4 represents the finite element models for the three studied load cases. Model idealization was achieved through a dimensional reduction of pressure vessel model into a 2D shell model, to reduce the computational time without decreasing the precision of the numerical results.

Shell elements are essentially suitable for shell structures with thin to moderately-thick thicknesses.

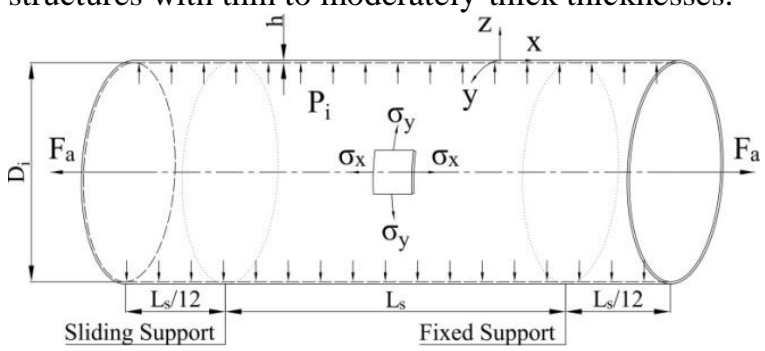

(a) Pure pressure load case

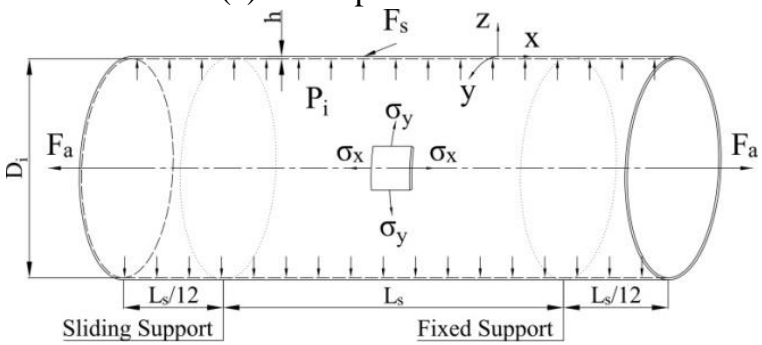

(b) Operating load case

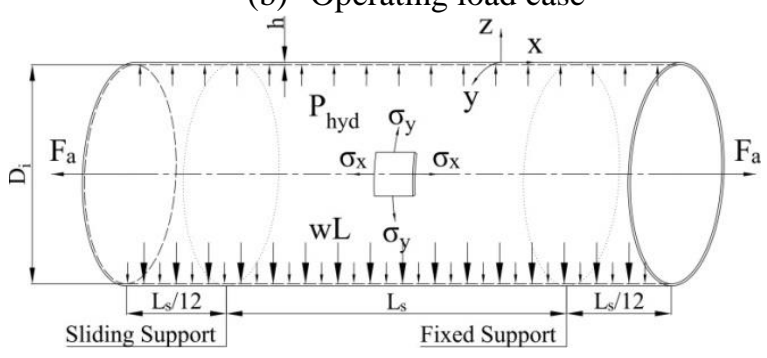

(c) Hydro-test load case

Fig. 3 Load combination and boundary conditions of three-phase separator pressure vessel for every load case

Model idealization was achieved through a dimensional reduction of pressure vessel model into a 2D shell model, to reduce the computational time without decreasing the precision of the numerical results. Shell elements are essentially suitable for shell structures with thin to moderately-thick thicknesses.

Mesh dependency is a measure of solution sensitivity towards meshing parameters: mesh density, type of element, number of elements and number of nodes used in defining the concerned model. Mesh resolution is a substantial aspect when discretizing scoped body; the higher the mesh resolution the more precious results are obtained. On the other hand, the higher the mesh resolution, the higher the simulation time consumed. Reasonable meshing resolution is adopted to obtain results with acceptable deviation and proper solving time. 
The size of the elements was chosen to be $150 \mathrm{~mm}$ and the mesh consisted of 7568 elements and 7642 nodes. Element SHELL181 which is a four-node element, having six degrees of freedom (DOF) at each node, three transitional and three rotational, was used to simulate composite pressure vessel [28]. The size of the elements was chosen carefully after mesh dependency check testing to keep error ratio under $1 \%$ for pure pressure load case and $2 \%$ for operating load case. Parametric models were constructed for every load case employing the design point parameters in ANSYS Workbench to provide a timesaving and error-free solving procedure.

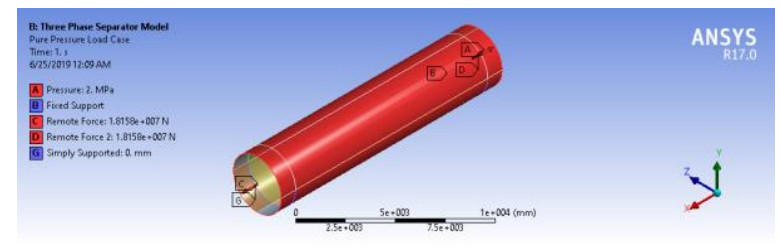

(a) Pure pressure load case

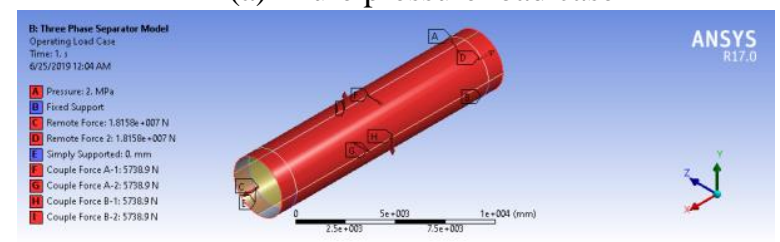

(b) Operating load case

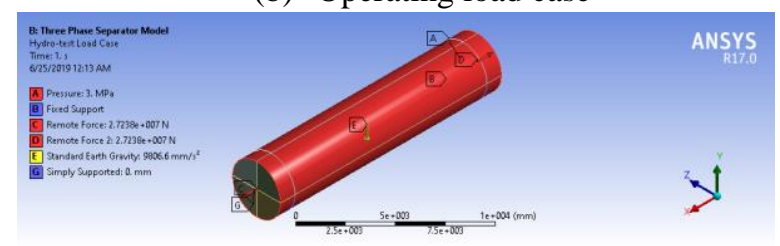

(c) Hydro-test load case

Fig. 4 Finite element model for three-phase separator pressure vessel for every load case

The required input was restricted only to the number of layers and winding angles for the three models. For operating load case the input was extended to the loading ratio $\mathrm{N}_{\mathrm{s}} / \mathrm{N}_{\mathrm{x}}$. On the other hand, for the hydrotest load case, the input was extended to introduce or suppress the water content. The corresponding safety factor for every load case was introduced as an output.

A Lenovo ThinkPad E550 laptop - processor Intel® Core $^{\mathrm{TM}}$ i7-5500U CPU speed of $2.4 \mathrm{GHz}$ and RAM of $16 \mathrm{~GB}$ with Windows 10-64 bit operating system was utilized for performing the required analysis.

\section{RESULTS AND DISCUSSION \\ 5.1 Mathematical solution \\ i. $\quad$ Pure pressure load case}

The mathematical results curves, for all examined layups and configurations were subjected to pure pressure only are reported in Fig. 5. Focusing on the curves, the minimum allowable structural thickness varies depending on the winding angle for every layup.

Table II summarizes the optimum winding angle, minimum allowable structural thickness and the corresponding safety factor for every lay-up for both mathematical and FEM solutions. The optimum layup winding angle for every lay-up configuration and the corresponding minimum allowable structural wall thickness for investigated filament-wound pressure vessels were related to filament properties. The data obtained from the mathematical solution were broadly consistent with the major trends in reference [19]. However, different filaments were used some lay-ups conducted the same winding angle Due to different filaments used, slight differences in optimum lay-up winding angles regarding neat layups and hybrid lay-ups from those in reference were obtained. Except for $[0 \mathrm{G},+90 \mathrm{G},-90 \mathrm{C}]_{11 \mathrm{~s} \text {, and }}$ $[90 \mathrm{C}, \pm 0 \mathrm{G}]_{8 \mathrm{~s}}$ higher differences were obtained $11^{\circ}$, and $26^{\circ}$ respectively.

Quit unexpected findings were obtained, for the hybrid fibers lay-up configurations $[+\theta \mathrm{C} /-\theta \mathrm{G}]_{\mathrm{ns}}$, $[0 \mathrm{C}, \pm \theta \mathrm{G}]_{\mathrm{ns}}$ and $[90 \mathrm{G},+\theta \mathrm{G},-\theta \mathrm{C}]_{\mathrm{ns}}$ compared with previous work [19], the allowable thickness was found to be higher than both allowable thickness required for S-glass and carbon/epoxy. This means that introducing higher properties fibers to lower properties not necessarily improves resistance to pure internal pressure but also it may consume higher number of layers than both neat configurations, the most likely explanation of the those results related to $[+\theta \mathrm{C} /-\theta \mathrm{G}]_{\mathrm{ns}}$ and $[90 \mathrm{G},+\theta \mathrm{G},-\theta \mathrm{C}]_{\mathrm{ns}}$ configurations could be the existence of unbalanced laminates and different material properties from those used in the previously mentioned work.

\section{ii. Operating load case}

The mathematical results, for all examined layups and configurations subjected to a combination of internal pressure and torsional force effect, are reported in Fig. 6. Those plots outline the change of the safety factor over the change of shear/longitudinal force per unit length $\mathrm{N}_{\mathrm{s}} / \mathrm{N}_{\mathrm{x}}$. Table III summarizes the ratio at which the failure occurs using both mathematical and FEM solutions. 
Figure 6.a depicts the change in the safety factor for the lay-up configuration $[ \pm \theta]_{\mathrm{ns}}$. The safety factor decreased gradually for $[ \pm 55.6 \mathrm{G}]_{16 \mathrm{~s}},[ \pm 54.3 \mathrm{C}]_{6 \mathrm{~s}}$, and $[ \pm 54.6 \mathrm{C}, \pm 54.6 \mathrm{G}]_{5 \mathrm{~s}}$ until failure was detected at adjacent values then the safety values decreases quietly. This consistency in behavior is reasonable because the winding angles for helical layers values are nearly equal. Whereas, for the lay-up [+54.7C,$54.7 \mathrm{G}]_{20}$ safety factor dramatically increases until reaching a peak at value of $\mathrm{N}_{\mathrm{S}} / \mathrm{N}_{\mathrm{x}}=0.9$ and the corresponding safety factor was $\mathrm{S}_{\mathrm{f}}=4.8492$ then the safety factor fell quickly until failure detected at $\mathrm{N}_{\mathrm{S}} / \mathrm{N}_{\mathrm{x}}=3$. It could be conceivably hypothesized that the unbalanced laminates that increased the resultant resistance to the combination of internal pressure and torsional force exerted by piping attached to the midspan nozzle. The reasons for this result are not yet wholly understood. Superior combined load carrying capacity for recently discussed lay-up made it the most suitable for high torsional in-plane circumference moment rates compared to the pure pressure applied at the same moment.

Figure 6.b shows the change in the safety factor for the lay-up configuration $[0, \pm \theta]_{\mathrm{ns}}$. Safety factor is decreased quickly till failure occurs at quasi values for $[0, \pm 90 \mathrm{G}]_{13 \mathrm{~s}}, \quad[0 \mathrm{C}, \pm 90 \mathrm{G}]_{16 \mathrm{~s}}, \quad$ and $[0 \mathrm{G},+90 \mathrm{G},-$ $90 \mathrm{C}]_{11 \mathrm{~s}}$. There were no significant differences between the three lay-up configurations in terms of the safety factor. On the other hand, for the pure carbon/epoxy lay-up $[0, \pm 90 \mathrm{C}]_{5 \mathrm{~s}}$, the safety factor dropped sharply till failure occurs at just over $40 \%$ of $\mathrm{N}_{\mathrm{s}} / \mathrm{N}_{\mathrm{x}}$ value executed compared with the above mentioned three lay-ups. This result shows an unexpected incompetent resistance to combined internal pressure and torsional force, however, the same lay-up configuration exhibit the highest safety factor value in this lay-up when exposed to pure pressure load case. The most likely explanation of this negative outcome is the existence of carbon/epoxy in hoop and axial layers, and lack of helical layers.

Figure 6.c depicts the change in the safety factor for the lay-up configuration $[90, \pm \theta]_{\mathrm{ns}}$. For carbon/epoxy and S-glass/epoxy, the safety factors were decreasing. However, the carbon/epoxy lay-up initial safety factor's value was higher, the S-glass/epoxy lay-up showed decreasing of safety factor with less rate. This made it a better solution for higher nozzle torsional load applications. For hybrid composite lay-ups, safety factor reduced moderately for the layup $[90 \mathrm{G},+48.9 \mathrm{G},-48.9 \mathrm{C}]_{12 \mathrm{~s}}$ while, the reduction in safety factor is considerably more critical for the layup $[90 \mathrm{C}, \pm 0 \mathrm{G}]_{8 \mathrm{~s}}$ showing weakened reluctance to combined loading condition which set a limited capacity for applying of nozzles suffering from high circumference moment rates. The hybrid lay-up $[90 \mathrm{G},+48.9 \mathrm{G},-48.9 \mathrm{C}]_{12 \mathrm{~s}}$ showed the lowest reduction rate in the safety factor.

Fig. 6.d shows the change in the safety factor for the lay-up configuration $[0, \pm \theta, 90]_{\mathrm{ns}}$. For carbon/epoxy and S-glass/epoxy, the safety factor was felling rapidly almost at equal rates till failure. For hybrid composite lay-ups, the safety factor was reduced moderately for $[0 \mathrm{G}, \pm 58.3 \mathrm{C}, 90 \mathrm{G}]_{5 \mathrm{~s}}$ while, safety factor was dropped markedly for $[0 \mathrm{C}, \pm 90 \mathrm{G}, 90 \mathrm{C}]_{6 \mathrm{~s}}$. However, the existence of carbon/epoxy was equal in both hybrid lay-ups. A considerable variance in combined loading condition resistance was observed. This result became in conformance with previously illustrated results stating that the existence of carbon/epoxy in hoop and axial layers and lack of helical layers lead to lower withstanding capacity to internal pressure and torsional load combination.

Fig. 6.e illustrates the change in the safety factor for the lay-up configuration $[90, \pm \theta, 90]_{\mathrm{ns}}$. For carbon/epoxy and S-glass/epoxy, the safety factor was decreased substantially approximately at the same rate until failure occurred. However, the higher stiffness carbon/epoxy lay-up were represented at the same level for both hybrid lay-ups, the existence in form of helical layers in the lay-up configuration $[90 \mathrm{G}, \pm 49.6 \mathrm{C}, 90 \mathrm{G}]_{5 \mathrm{~s}}$ improved the resistance for the combined internal pressure and torsional load applied compared with lay-up configuration $[90 \mathrm{C}, \pm 0 \mathrm{G}, 90 \mathrm{C}]_{5 \mathrm{~s}}$ which contain the carbon/epoxy in form of hoop layers. This built confidence towards the deduction that the lack of helical layers in lay-up configurations containing carbon/epoxy layers reduces the combined internal pressure and torsional force resistance capacity. 


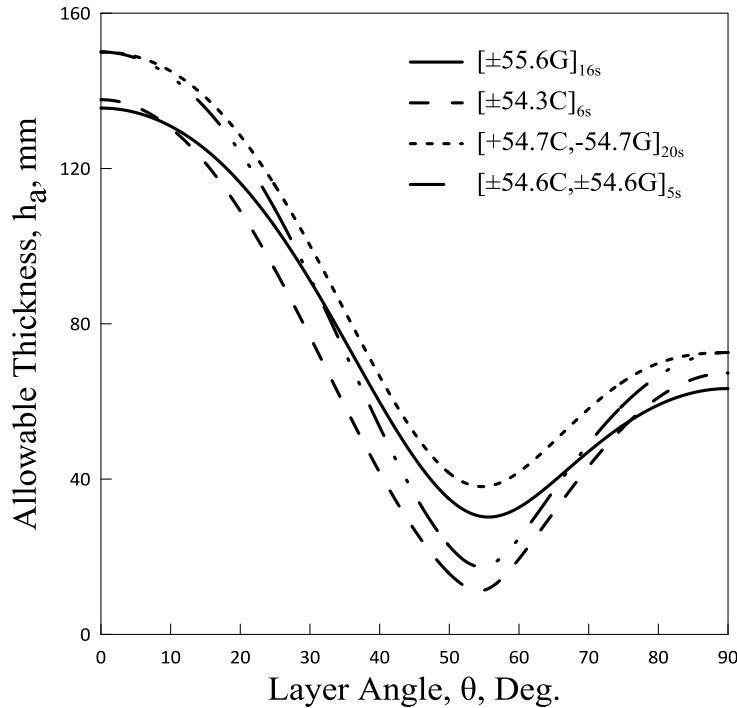

(a) Lay-up configuration $[ \pm \theta]_{\mathrm{ns}}$

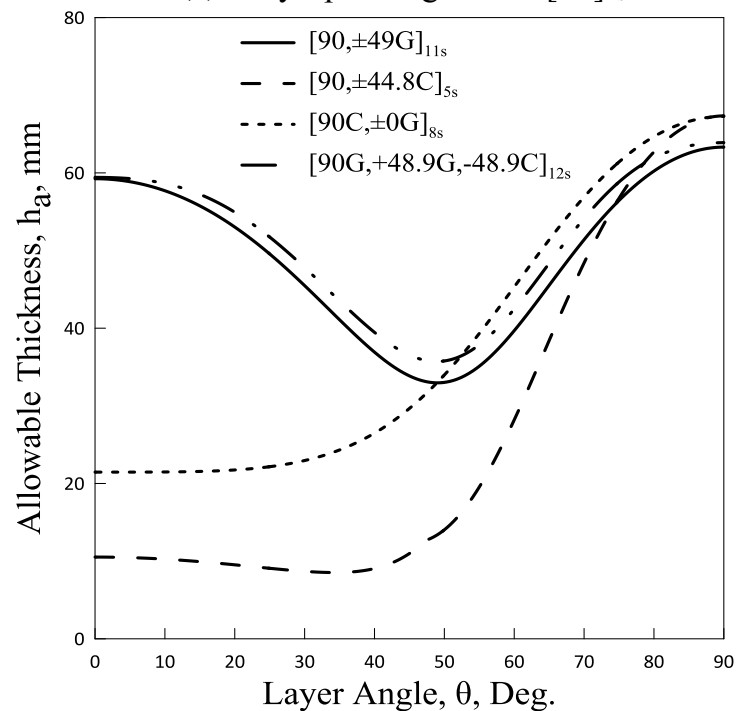

(c) Lay-up configuration $[90, \pm \theta]_{\mathrm{ns}}$

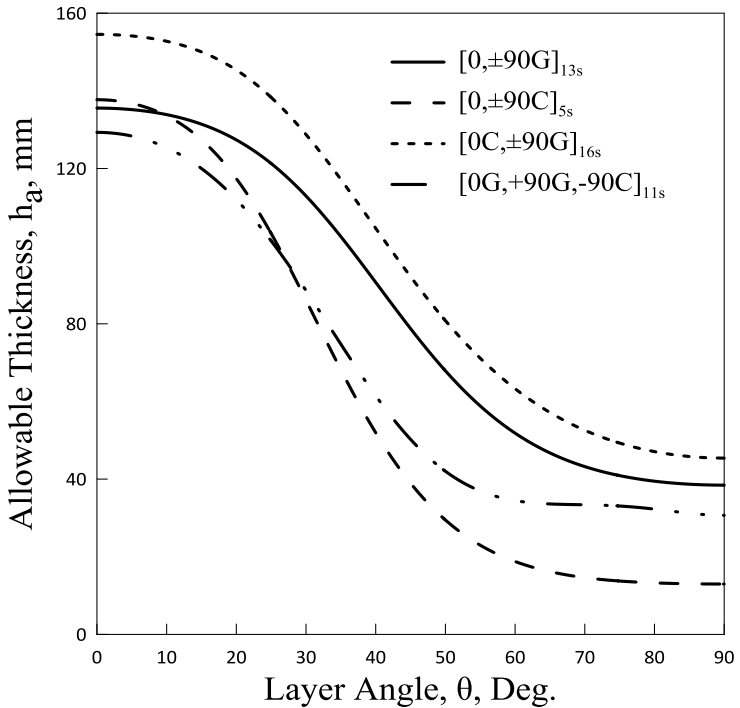

(b) Lay-up configuration $[0, \pm \theta]_{\mathrm{ns}}$

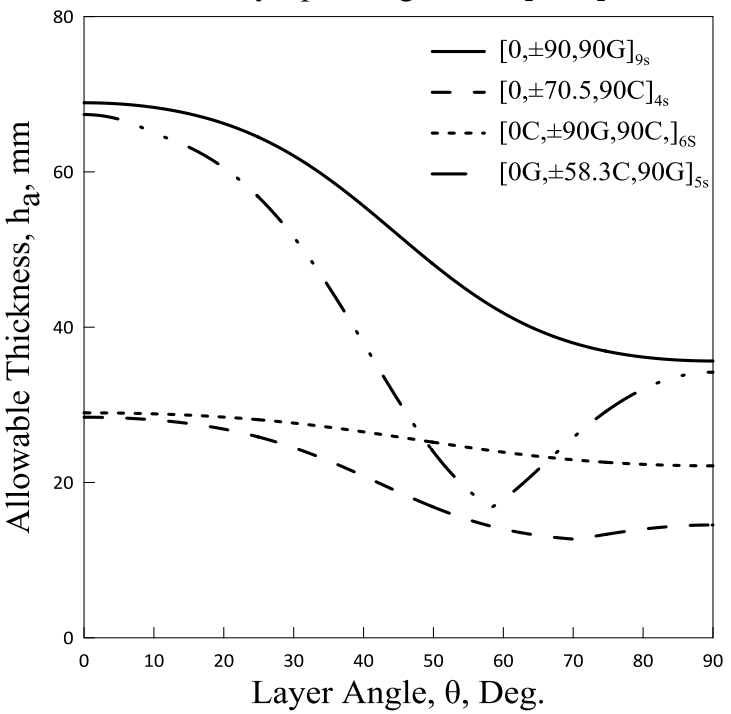

(d) Lay-up configuration $[0, \pm \theta, 90]_{\mathrm{ns}}$

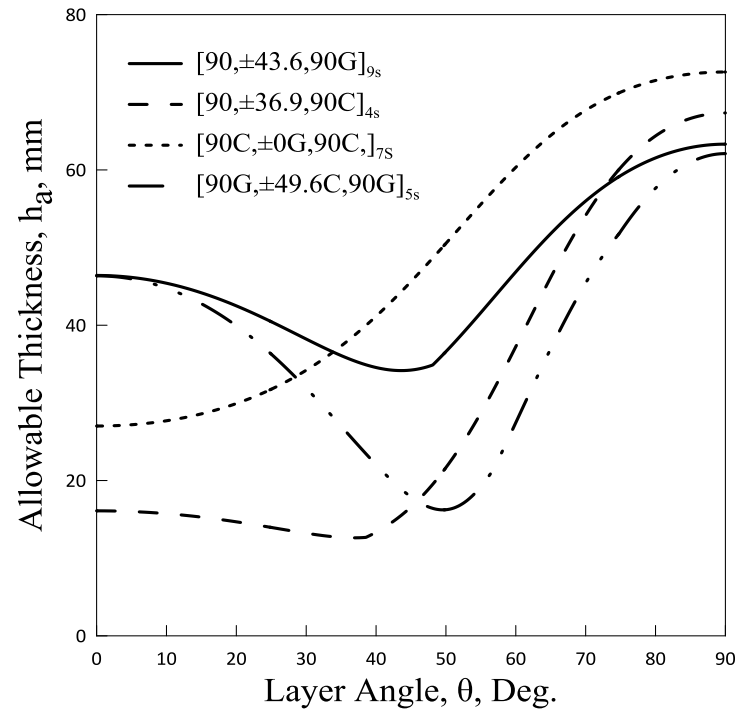

(e) Lay-up configuration $[90, \pm \theta, 90]_{\mathrm{ns}}$

Fig. 5 Variation of allowable thickness versus fiber orientation for every lay-up 
A. A. Hassan, M. Abo-Elkhier, B. Abd El-bary" EVALUATION OF OPTIMUM CON..."

Table II PRESSURE VESSEL WALL THICKNESS AND SAFETY FACTOR FOR PURE PRESSURE LOAD CASE

\begin{tabular}{|c|c|c|c|c|c|c|c|c|c|}
\hline \multirow{2}{*}{ Lay-up } & \multirow{2}{*}{ Material } & \multirow{2}{*}{ Optimum lay-up } & \multirow{2}{*}{$\mathrm{n}$} & \multicolumn{3}{|c|}{ Mathematical Solution } & \multicolumn{2}{|c|}{ FEM } & \multirow{2}{*}{$\Delta \mathrm{S}_{\mathrm{f}} \%$} \\
\hline & & & & $\mathrm{h}_{\mathrm{a}}$ & $\mathrm{h}$ & $S_{\mathrm{f}}$ & $\mathrm{h}$ & $S_{\mathrm{f}}$ & \\
\hline \multirow{4}{*}[\pm\theta]{$_{\mathrm{ns}}$} & S-glass/epoxy & {$[ \pm 55.6 \mathrm{G}]_{16 \mathrm{~s}}$} & 16 & 30.2300 & 32 & 2.1171 & 32 & 2.1180 & 0.0425 \\
\hline & Carbon/epoxy & {$[ \pm 54.3 \mathrm{C}]_{6 \mathrm{~s}}$} & 6 & 11.2318 & 12 & 2.1368 & 12 & 2.1348 & -0.0936 \\
\hline & {$[+\theta \mathrm{C},-\theta \mathrm{G}]_{\mathrm{ns}}$} & {$[+54.7 \mathrm{C},-54.7 \mathrm{G}]_{20 \mathrm{~s}}$} & 20 & 38.0697 & 40 & 2.1014 & 40 & 2.1126 & 0.5330 \\
\hline & {$[ \pm \theta \mathrm{C}, \pm \theta \mathrm{G}]_{\mathrm{ns}}$} & {$[ \pm 54.6 \mathrm{C}, \pm 54.6 \mathrm{G}]_{5 \mathrm{~s}}$} & 5 & 17.3996 & 20 & 2.2989 & 20 & 2.2979 & -0.0435 \\
\hline \multirow{4}{*}[0,\pm\theta]{$_{\mathrm{ns}}$} & S-glass/epoxy & {$[0, \pm 90 \mathrm{G}]_{13 \mathrm{~s}}$} & 13 & 38.4440 & 39 & 2.0289 & 39 & 2.0142 & -0.7245 \\
\hline & Carbon/epoxy & {$[0, \pm 90 \mathrm{C}]_{5 \mathrm{~s}}$} & 5 & 12.9755 & 15 & 2.3121 & 15 & 2.3036 & -0.3676 \\
\hline & {$[0 \mathrm{C}, \pm \theta \mathrm{G}]_{\mathrm{ns}}$} & {$[0 \mathrm{C}, \pm 90 \mathrm{G}]_{16 \mathrm{~s}}$} & 16 & 45.4121 & 48 & 2.1140 & 48 & 2.1144 & 0.0189 \\
\hline & {$[0 \mathrm{G},+\theta \mathrm{G},-\theta \mathrm{C}]_{\mathrm{ns}}$} & {$[0 \mathrm{G},+90 \mathrm{G},-90 \mathrm{C}]_{11 \mathrm{~s}}$} & 11 & 30.6714 & 33 & 2.1518 & 33 & 2.1355 & -0.7575 \\
\hline \multirow{4}{*}[90,\pm\theta]{$_{\mathrm{ns}}$} & S-glass/epoxy & {$[90, \pm 49 \mathrm{G}]_{11 \mathrm{~s}}$} & 11 & 32.9635 & 33 & 2.0022 & 33 & 2.0029 & 0.0350 \\
\hline & Carbon/epoxy & {$[90, \pm 44.8 \mathrm{C}]_{5 \mathrm{~s}}$} & 5 & 12.2902 & 15 & 2.4410 & 15 & 2.4389 & -0.0860 \\
\hline & {$[90 \mathrm{C}, \pm \theta \mathrm{G}]_{\mathrm{ns}}$} & {$[90 \mathrm{C}, \pm 0 \mathrm{G}]_{8 \mathrm{~s}}$} & 8 & 23.3563 & 24 & 2.0551 & 24 & 2.0517 & -0.1654 \\
\hline & {$[90 \mathrm{G},+\theta \mathrm{G},-\theta \mathrm{C}]_{\mathrm{ns}}$} & {$[90 \mathrm{G},+48.9 \mathrm{G},-48.9 \mathrm{C}]_{12 \mathrm{~s}}$} & 12 & 35.7149 & 36 & 2.0160 & 36 & 2.0131 & -0.1438 \\
\hline \multirow{4}{*}[0,\pm\theta,90]{$_{\mathrm{ns}}$} & S-glass/epoxy & {$[0, \pm 90 \mathrm{G}, 90]_{9 \mathrm{~s}}$} & 9 & 35.6461 & 36 & 2.0199 & 36 & 2.0153 & -0.2277 \\
\hline & Carbon/epoxy & {$[0, \pm 70.5 \mathrm{C}, 90]_{4 \mathrm{~s}}$} & 4 & 12.6829 & 16 & 2.5231 & 16 & 2.5157 & -0.2933 \\
\hline & {$[0 \mathrm{C}, \pm \theta \mathrm{G}, 90 \mathrm{C}]_{\mathrm{ns}}$} & {$[0 \mathrm{C}, \pm 90 \mathrm{G}, 90 \mathrm{C}]_{6 \mathrm{~s}}$} & 6 & 22.1487 & 24 & 2.1672 & 24 & 2.1618 & -0.2492 \\
\hline & {$[0 \mathrm{G}, \pm \theta \mathrm{C}, 90 \mathrm{G}]_{\mathrm{ns}}$} & {$[0 \mathrm{G}, \pm 58.3 \mathrm{C}, 90 \mathrm{G}]_{5 \mathrm{~s}}$} & 5 & 16.7980 & 20 & 2.3812 & 20 & 2.3873 & 0.2562 \\
\hline \multirow{4}{*}[90,\pm\theta,90]{$_{\mathrm{ns}}$} & S-glass/epoxy & {$[90, \pm 43.6 \mathrm{G}, 90]_{9 \mathrm{~s}}$} & 9 & 34.1594 & 36 & 2.1078 & 36 & 2.1077 & -0.0047 \\
\hline & Carbon/epoxy & {$[90, \pm 36.9 \mathrm{C}, 90]_{4 \mathrm{~s}}$} & 4 & 12.6221 & 16 & 2.5352 & 16 & 2.5219 & -0.5246 \\
\hline & {$[90 \mathrm{C}, \pm \theta \mathrm{G}, 90 \mathrm{C}]_{\mathrm{ns}}$} & {$[90 \mathrm{C}, \pm 0 \mathrm{G}, 90 \mathrm{C}]_{7 \mathrm{~s}}$} & 7 & 27.0197 & 28 & 2.0726 & 28 & 2.0760 & 0.1640 \\
\hline & {$[90 \mathrm{G}, \pm \theta \mathrm{C}, 90 \mathrm{G}]_{\mathrm{ns}}$} & {$[90 \mathrm{G}, \pm 49.6 \mathrm{C}, 90 \mathrm{G}]_{5 \mathrm{~s}}$} & 5 & 16.2237 & 20 & 2.4655 & 20 & 2.4610 & -0.1825 \\
\hline
\end{tabular}




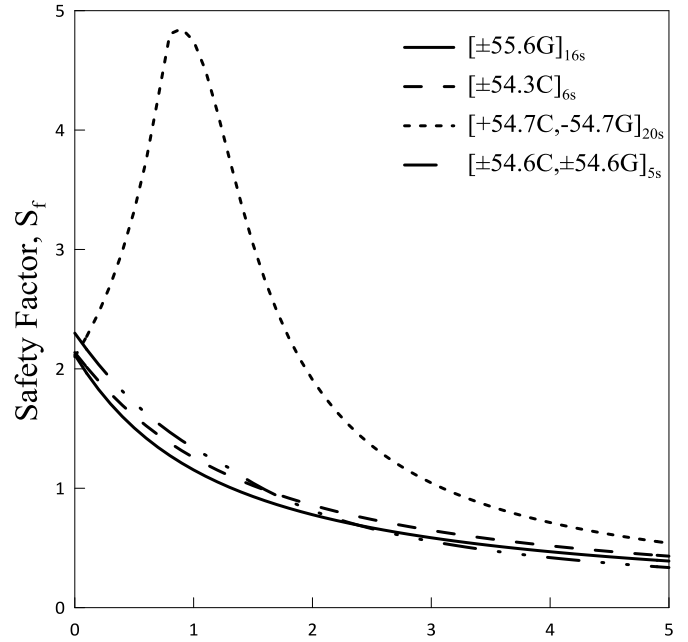

Shear/Longitudinal force per unit length, $\mathrm{N}_{\mathrm{s}} / \mathrm{N}_{\mathrm{x}}$

(a) Lay-up configuration $[ \pm \theta]_{\mathrm{ns}}$

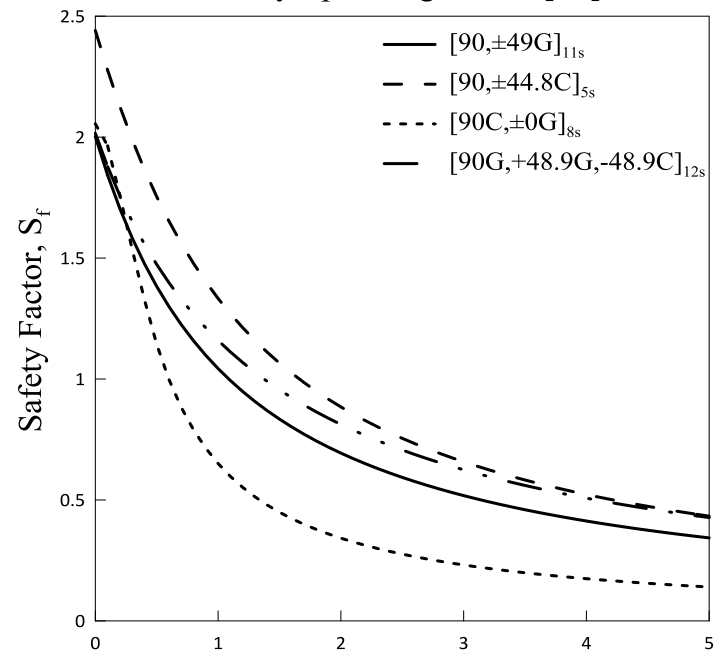

Shear/Longitudinal force per unit length, $\mathrm{N}_{\mathrm{s}} / \mathrm{N}_{\mathrm{x}}$

(c) Lay-up configuration $[90, \pm \theta]_{\mathrm{ns}}$

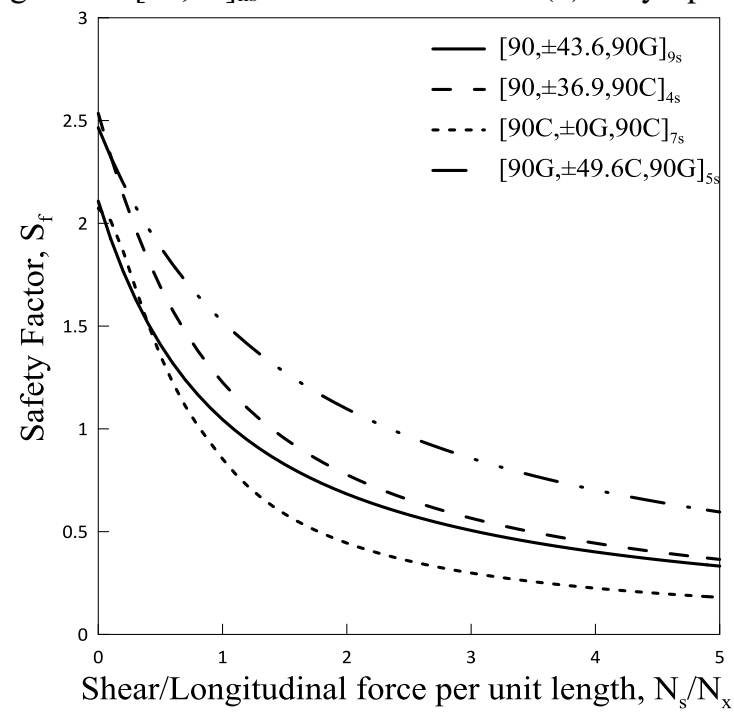

(e) Lay-up configuration $[90, \pm \theta, 90]_{\mathrm{ns}}$

Fig. 6 Variation of safety factor versus shear/longitudinal force per unit length $N_{s} / N_{x}$

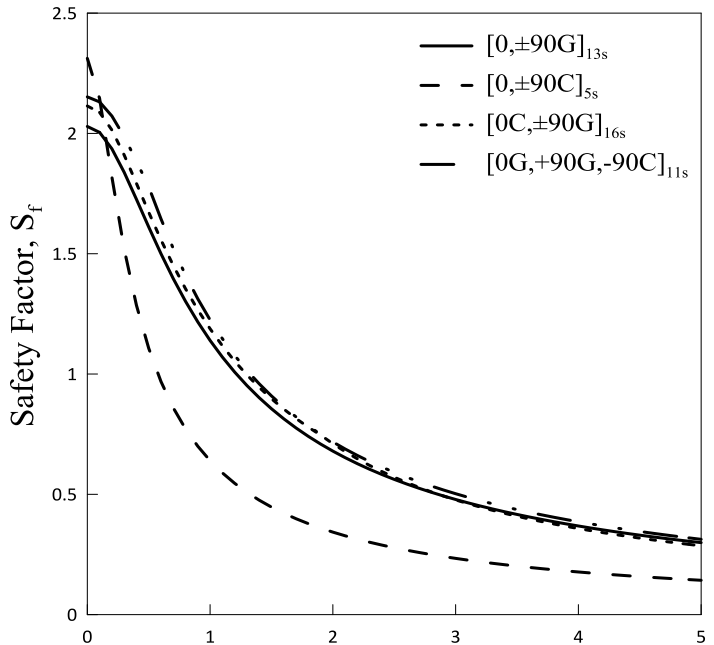

Shear/Longitudinal force per unit length, $\mathrm{N}_{\mathrm{s}} / \mathrm{N}_{\mathrm{x}}$

(b) Lay-up configuration $[0, \pm \theta]_{\mathrm{ns}}$

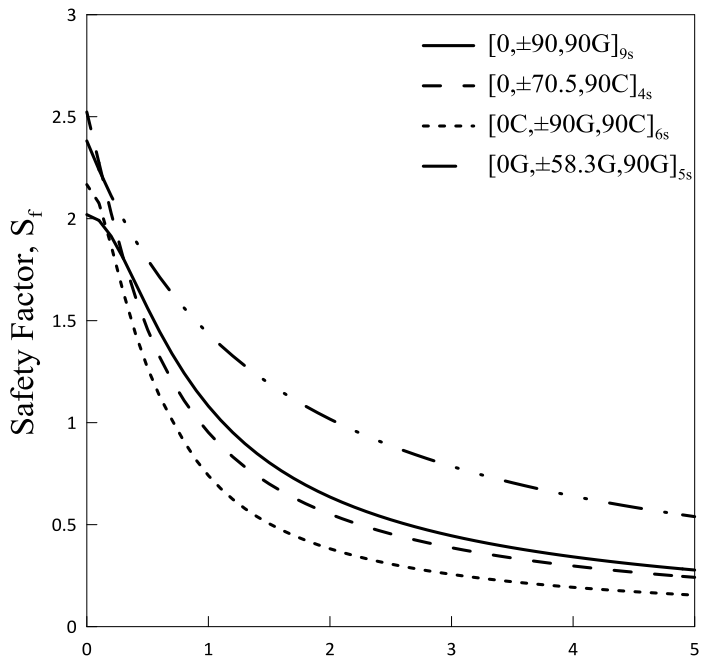

Shear/Longitudinal force per unit length, $\mathrm{N}_{\mathrm{s}} / \mathrm{N}_{\mathrm{x}}$

(d) Lay-up configuration $[0, \pm \theta, 90]_{\mathrm{ns}}$ 
Table III SAFETY FACTOR FOR OPERATING LOAD CASE

\begin{tabular}{|c|c|c|c|c|c|}
\hline \multirow[t]{2}{*}{ Lay-up } & \multirow[t]{2}{*}{ Optimum lay-up } & \multirow[t]{2}{*}{$\mathrm{N}_{\mathrm{s}} / \mathrm{N}_{\mathrm{x}}$} & $\begin{array}{c}\text { Mathematical } \\
\text { Solution }\end{array}$ & FEM & \multirow[t]{2}{*}{$\Delta \mathrm{S}_{\mathrm{f}} \%$} \\
\hline & & & $\mathrm{S}_{\mathrm{f}}$ & $\mathrm{S}_{\mathrm{f}}$ & \\
\hline \multirow{4}{*}[\pm\theta]{$_{\mathrm{ns}}$} & {$[ \pm 55.6 \mathrm{G}]_{16 \mathrm{~s}}$} & 1.3 & 1.0089 & 1.0094 & 0.0531 \\
\hline & {$[ \pm 54.3 \mathrm{C}]_{6 \mathrm{~s}}$} & 1.5 & 1.0223 & 1.0218 & -0.0483 \\
\hline & {$[+54.7 \mathrm{C},-54.7 \mathrm{G}]_{20 \mathrm{~s}}$} & 3 & 1.0445 & 1.0639 & 1.8536 \\
\hline & {$[ \pm 54.6 \mathrm{C}, \pm 54.6 \mathrm{G}]_{5 \mathrm{~s}}$} & 1.5 & 1.0431 & 1.0529 & 0.9411 \\
\hline \multirow{4}{*}[0,\pm\theta]{$_{\mathrm{ns}}$} & {$[0, \pm 90 \mathrm{G}]_{13 \mathrm{~s}}$} & 1.2 & 1.0082 & 1.0031 & -0.5069 \\
\hline & {$[0, \pm 90 \mathrm{C}]_{5 \mathrm{~s}}$} & 0.5 & 1.1070 & 1.1132 & 0.5597 \\
\hline & {$[0 \mathrm{C}, \pm 90 \mathrm{G}]_{16 \mathrm{~s}}$} & 1.2 & 1.0536 & 1.0629 & 0.8802 \\
\hline & {$[0 \mathrm{G},+90 \mathrm{G},-90 \mathrm{C}]_{11 \mathrm{~s}}$} & 1.3 & 1.0152 & 1.0132 & -0.1988 \\
\hline \multirow{4}{*}[90,\pm\theta]{$_{\mathrm{ns}}$} & {$[90, \pm 49 \mathrm{G}]_{11 \mathrm{~s}}$} & 1 & 1.0431 & 1.0257 & -0.3355 \\
\hline & {$[90, \pm 44.8 \mathrm{C}]_{5 \mathrm{~s}}$} & 1.6 & 1.0241 & 1.0152 & $0.361 r$ \\
\hline & {$[90 \mathrm{C}, \pm 0 \mathrm{G}]_{8 \mathrm{~s}}$} & 0.5 & 1.1429 & 1.1602 & 1.5112 \\
\hline & {$[90 \mathrm{G},+48.9 \mathrm{G},-48.9 \mathrm{C}]_{12 \mathrm{~s}}$} & 1.3 & 1.0277 & 1.0404 & 1.2318 \\
\hline \multirow{4}{*}[0,\pm\theta,90]{$_{\mathrm{ns}}$} & {$[0, \pm 90 \mathrm{G}, 90]_{9 \mathrm{~s}}$} & 1.1 & 1.0130 & 1.0125 & -0.0478 \\
\hline & {$[0, \pm 70.5 \mathrm{C}, 90]_{4 \mathrm{~s}}$} & 0.9 & 1.0248 & 1.0256 & 0.0777 \\
\hline & {$[0 \mathrm{C}, \pm 90 \mathrm{G}, 90 \mathrm{C}]_{6 \mathrm{~s}}$} & 0.7 & 1.0143 & 1.0262 & 1.1717 \\
\hline & {$[0 \mathrm{G}, \pm 58.3 \mathrm{C}, 90 \mathrm{G}]_{5 \mathrm{~s}}$} & 2 & 1.0174 & 1.0295 & 1.1890 \\
\hline \multirow{4}{*}[90,\pm\theta,90]{$_{\mathrm{ns}}$} & {$[90, \pm 43.6 \mathrm{G}, 90]_{9 \mathrm{~s}}$} & 1 & 1.0454 & 1.0461 & 0.0675 \\
\hline & {$[90, \pm 36.9 \mathrm{C}, 90]_{4 \mathrm{~s}}$} & 1.3 & 1.0469 & 1.0452 & -0.1621 \\
\hline & {$[90 \mathrm{C}, \pm 0 \mathrm{G}, 90 \mathrm{C}]_{7 \mathrm{~s}}$} & 0.8 & 1.0156 & 1.0011 & -1.4242 \\
\hline & {$[90 \mathrm{G}, \pm 49.6 \mathrm{C}, 90 \mathrm{G}]_{5 \mathrm{~s}}$} & 2.3 & 1.0121 & 1.0267 & 1.4471 \\
\hline
\end{tabular}

\subsection{Finite element analysis solution}

For design safety assessment, a finite element model was developed for the multilayered filament-wound PV simulation. Pressure vessel model simplified geometry was created in ANSYS Design modeler. The mechanical model was created and static structural analysis was done using Mechanical APDL solver. Ply materials and stack-up were defined to represent the concerned lay-up configurations using ANSYS ACP (Pre). Tsai-Wu failure criteria was introduced in ANSYS ACP (Post) ANSYS in terms of Reserve factor (RF) which is a measure of design safety representing the safety factor. Workbench design point parameters were used for creating configurable models and facilitate parametric study. The whole obtained FE analysis results were compared with mathematical solution results in terms of safety factor which showed good agreement. Project schematic is showed in Fig. 7.

\section{i. $\quad$ Pure pressure load case}

As previously indicated in Table II, safety factor values from both solutions were compared. The FEM solution showed that the safety factor value is uniformly distributed on the external surface of the cylindrical shell indicating the effect of applying uniformly distributed internal design pressure. Some inconsequential safety factor values were observed at two types of locations. Firstly, at both ends, pseudoaxial thrust forces were applied at the vessel edges to simulate end caps. Unrealistic safety factor values were obtained due to applying these loads in form of remote normal force affecting on the circular edge [29]. These values can be ignored because the scoped area was at a sufficient distance from loading edges [27]. Secondly, singularities at saddles locations boundary conditions are represented at both front sliding support and fixed rear support that also was ignored because the very high stiffness of such supports are not existing practically, and in the real 
saddles manufacturing, higher lamination thicknesses are considered because of stress concentration. Fig. 8 shows the top and bottom view of the safety factor distribution over the PV external surface for the layup $[ \pm 54.6 \mathrm{C}, \pm 54.6 \mathrm{G}]_{5 \mathrm{~s}}$. Safety factor value was obtained using probe over the span portion between saddles.

\section{ii. Operating load case}

The same model used for pure pressure load case was developed introducing the shear torsional force at mid-span portion to simulate the effect of interconnecting piping attached to a mid-span nozzle. Furthermore, the local stresses due to the nozzle/vessel connection were underestimated. Nozzle's reinforcement pads provide are commonly applied to recover cut-out section from PV and to improve local stresses at nozzle/vessel connection. Global stress effects due to applied shear torsional force combined with internal design pressure were considered.

As previously indicated in Table III, safety factor values obtained from both solutions were compared. The FEM solution showed that the safety factor value is distributed in a form of value-graded uniform strips around the circumference of applied torsional force. No significant differences between top and bottom views were observed due to applying Saint-Venant's principle. The concerned safety factor value is achieved at the portion close to the fixed saddle. Rotation allowed at the sliding saddle that could be achieved in realistic application in case of the clamped saddle.

Fig. 9 outlines the safety factor distribution over the PV body for the lay-up $[ \pm 54.6 \mathrm{C}, \pm 54.6 \mathrm{G}]_{5 \mathrm{~s}}$ when applying loading ratio $\mathrm{N}_{\mathrm{s}} / \mathrm{N}_{\mathrm{x}}=1.3$. The distinct behavior of the lay-up $[+54.7 \mathrm{C},-54.7 \mathrm{G}]_{20 \mathrm{~s}}$ is represented in Fig. 10. As increasing loading ratio $\mathrm{N}_{\mathrm{s}} / \mathrm{N}_{\mathrm{x}}$ results in increased safety factor value till
$\mathrm{N}_{\mathrm{s}} / \mathrm{N}_{\mathrm{x}}=0.9$ achieving the highest safety factor value then, increasing loading ratio till $\mathrm{Ns} / \mathrm{Nx}=3$ failure occurs as indicated in Fig. 11. However, Sliding saddle should allow free rotation as a free end; increased safety factor value was observed near it which is not yet wholly understood.

\section{iii. Hydro-test load case}

For clearer characterization for the hydro-test load case firstly, the hydro-test pressure was introduced as uniformly distributed internal pressure without consideration for the total weight of PV and fluid content. The safety factor in such case is defined as hydro-test safety factor at zero span $\mathrm{S}_{\mathrm{fH}}$. Secondly, realistic hydro-test load case was simulated considering both hydro-test pressure and the total weight of PV and fluid content. Then safety factor is defined as the hydro-test safety factor $\mathrm{S}_{\mathrm{fH}}$. Finally, the reduction ratio in safety factor $\delta \mathrm{S}_{\mathrm{f}}$ values were calculated which was considered as an indicator of the effect of representing the total weight on the design safety. Table IV summarizes the reduction ratio in safety factor value for every lay-up. The analysis and simulation for all configurations lay-ups indicate initially that the neat S-glass/epoxy lay-ups showed lower reduction ratios in safety factors than those obtained in case of neat carbon/epoxy lay-ups. A quit expected result was that the lay-ups that contain a higher number of layers in the axial direction, as representing total weight of PV and fluid content is considered mainly as a source of bending stress which is a type of normal loading in form of tension and compression about the neutral axis. This made the load facing the strongest direction of filaments. As a result, increased resistance to combined hydro-test pressure and the total weight was obtained. Fig. 12 - Fig. 16 present lay-ups with lowest reduction ratios in the safety factor.

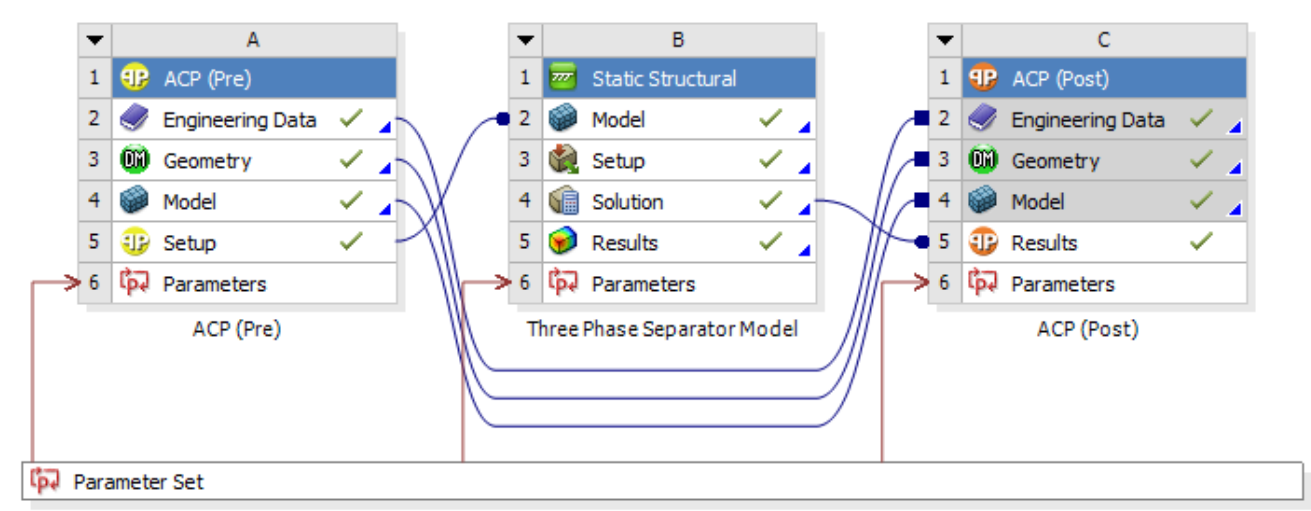

Fig. 7 ANSYS Workbench schematic 


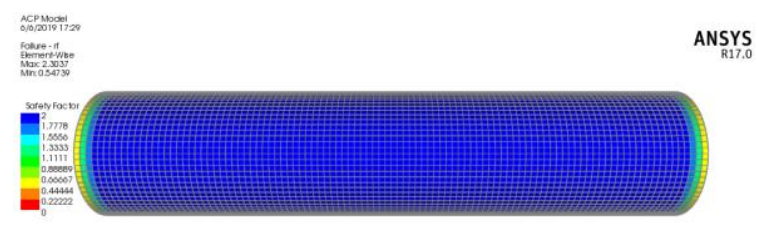

(a) Top view

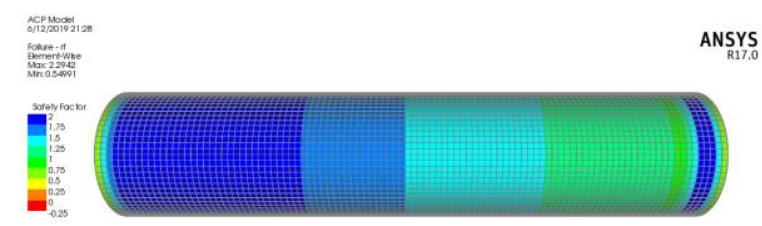

(a) Top view

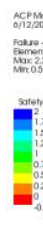

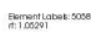

(b) Bottom view

Fig. 9 Operating load case: Safety factor distribution for the lay-up $[ \pm 54.6 \mathrm{C}, \pm 54.6 \mathrm{G}]_{5 \mathrm{~s}}$ at $\mathbf{N}_{\mathrm{s}} / \mathbf{N}_{\mathrm{x}}=\mathbf{1 . 3}$

distribution for the lay-up $[ \pm 54.6 \mathrm{C}, \pm 54.6 \mathrm{G}]_{5 \mathrm{~s}}$

Table IV REDUCTION IN SAFETY FACTOR FOR HYDRO-TEST LOAD CASE

\begin{tabular}{|c|c|c|c|c|}
\hline \multirow{2}{*}{ Lay-up } & \multirow{2}{*}{ Optimum lay-up } & \multicolumn{2}{|c|}{ FEM } & \multirow{2}{*}{$\delta \mathrm{S}_{\mathrm{f}} \%$} \\
\hline & & $\underline{\mathrm{S}_{\mathrm{fH} 0}}$ & $\mathrm{~S}_{\mathrm{fH}}$ & \\
\hline \multirow{4}{*}[\pm\theta]{$_{\mathrm{ns}}$} & {$[ \pm 55.6 \mathrm{G}]_{16 \mathrm{~s}}$} & 1.4120 & 1.2823 & -9.1856 \\
\hline & {$[ \pm 54.3 \mathrm{C}]_{6 \mathrm{~s}}$} & 1.4232 & 1.1277 & -20.7631 \\
\hline & {$[+54.7 \mathrm{C},-54.7 \mathrm{G}]_{20 \mathrm{~s}}$} & 1.4084 & 1.1559 & -17.9281 \\
\hline & {$[ \pm 54.6 \mathrm{C}, \pm 54.6 \mathrm{G}]_{5 \mathrm{~s}}$} & 1.5319 & 1.2721 & -16.9611 \\
\hline \multirow{4}{*}[0,\pm\theta]{$_{\mathrm{ns}}$} & {$[0, \pm 90 \mathrm{G}]_{13 \mathrm{~s}}$} & 1.3428 & 1.2105 & -9.8525 \\
\hline & {$[0, \pm 90 \mathrm{C}]_{5 \mathrm{~s}}$} & 1.5357 & 1.3011 & -15.2783 \\
\hline & {$[0 \mathrm{C}, \pm 90 \mathrm{G}]_{16 \mathrm{~s}}$} & 1.4096 & 1.3227 & -6.1649 \\
\hline & {$[0 \mathrm{G},+90 \mathrm{G},-90 \mathrm{C}]_{11 \mathrm{~s}}$} & 1.4237 & 1.3773 & -3.2568 \\
\hline \multirow{4}{*}[90,\pm\theta]{$_{\mathrm{ns}}$} & {$[90, \pm 49 \mathrm{G}]_{11 \mathrm{~s}}$} & 1.3353 & 1.2136 & -9.1118 \\
\hline & {$[90, \pm 44.8 \mathrm{C}]_{5 \mathrm{~s}}$} & 1.6259 & 1.3565 & -16.5710 \\
\hline & {$[90 \mathrm{C}, \pm 0 \mathrm{G}]_{8 \mathrm{~s}}$} & 1.3678 & 1.2823 & -6.2509 \\
\hline & {$[90 \mathrm{G},+48.9 \mathrm{G},-48.9 \mathrm{C}]_{12 \mathrm{~s}}$} & 1.3421 & 1.2102 & -9.8256 \\
\hline \multirow{4}{*}[0,\pm\theta,90]{$_{\mathrm{ns}}$} & {$[0, \pm 90 \mathrm{G}, 90]_{9 \mathrm{~s}}$} & 1.3435 & 1.2195 & -9.2319 \\
\hline & {$[0, \pm 70.5 \mathrm{C}, 90]_{4 \mathrm{~s}}$} & 1.6771 & 1.4335 & -14.5268 \\
\hline & {$[0 \mathrm{C}, \pm 90 \mathrm{G}, 90 \mathrm{C}]_{6 \mathrm{~s}}$} & 1.4412 & 1.2595 & -12.6075 \\
\hline & {$[0 \mathrm{G}, \pm 58.3 \mathrm{C}, 90 \mathrm{G}]_{5 \mathrm{~s}}$} & 1.5915 & 1.4152 & -11.0795 \\
\hline \multirow{4}{*}[90,\pm\theta,90]{$_{\mathrm{ns}}$} & {$[90, \pm 43.6 \mathrm{G}, 90]_{9 \mathrm{~s}}$} & 1.4051 & 1.2729 & -9.4107 \\
\hline & {$[90, \pm 36.9 \mathrm{C}, 90]_{4 \mathrm{~s}}$} & 1.6813 & 1.4334 & -14.7429 \\
\hline & {$[90 \mathrm{C}, \pm 0 \mathrm{G}, 90 \mathrm{C}]_{7 \mathrm{~s}}$} & 1.3840 & 1.2878 & -6.9509 \\
\hline & {$[90 \mathrm{G}, \pm 49.6 \mathrm{C}, 90 \mathrm{G}]_{5 \mathrm{~s}}$} & 1.6407 & 1.4282 & -12.9500 \\
\hline
\end{tabular}



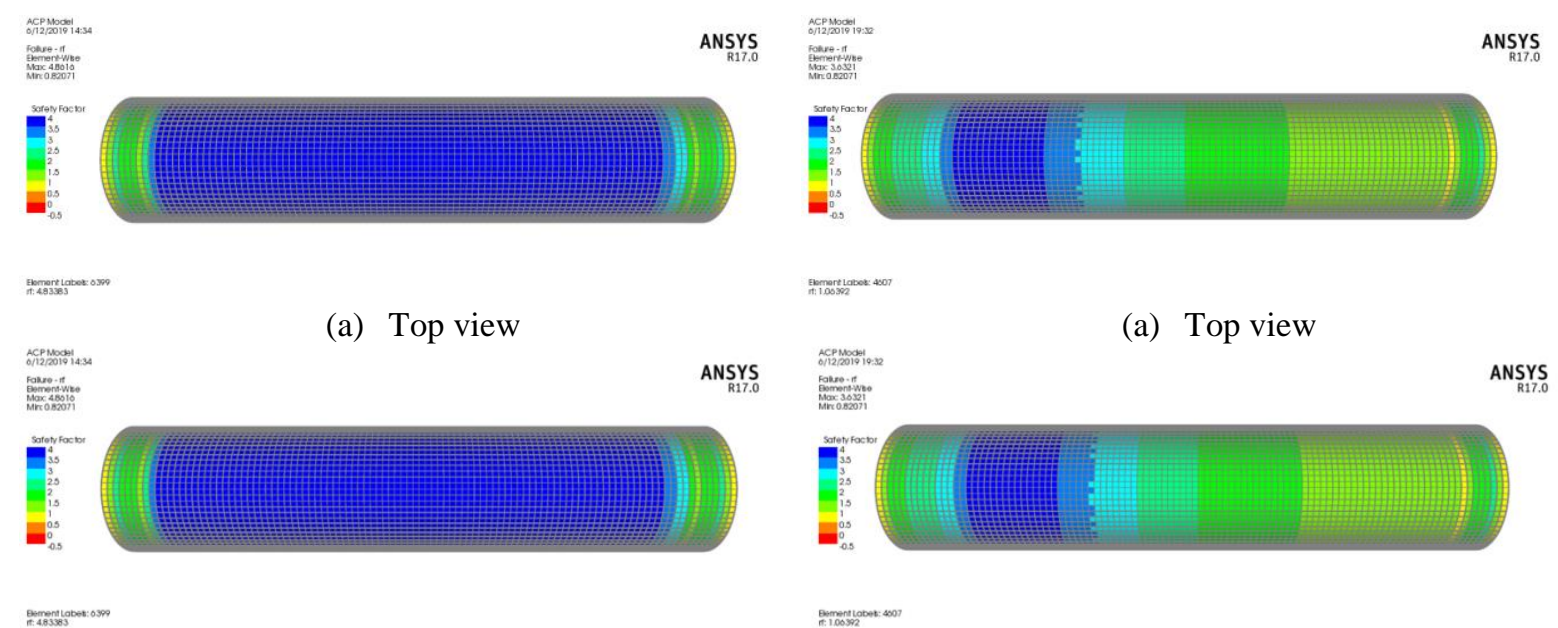

(b) Bottom view

(b) Bottom view

Fig. 10 Operating load case: Safety factor distribution for the lay-up $[+54.7 \mathrm{C},-54.7 \mathrm{G}]_{20 \mathrm{~s}}$ at $\mathbf{N}_{\mathrm{s}} / \mathbf{N}_{\mathrm{x}}=\mathbf{0 . 9}$

Fig. 11 Operating load case: Safety factor distribution for the lay-up $[+54.7 \mathrm{C},-54.7 \mathrm{G}]_{20 \mathrm{~s}}$ at $\mathbf{N}_{\mathrm{s}} / \mathbf{N}_{\mathbf{x}}=\mathbf{3}$
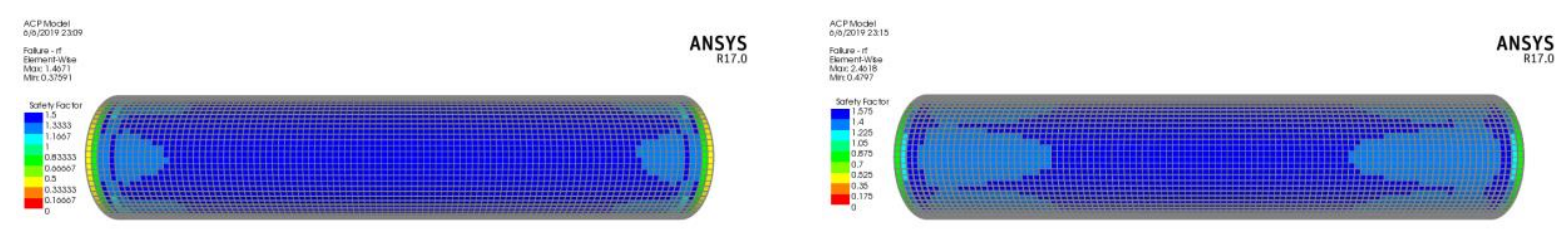

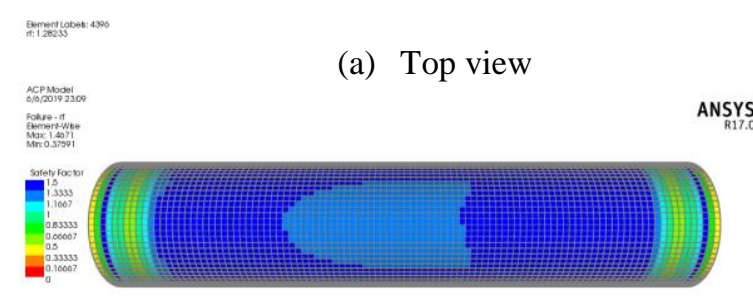

(b) Bottom view

Fig. 12 Hydro-test pressure load case: Safety factor distribution for the lay-up $[ \pm 55.6 \mathrm{G}]_{16 \mathrm{~s}}$
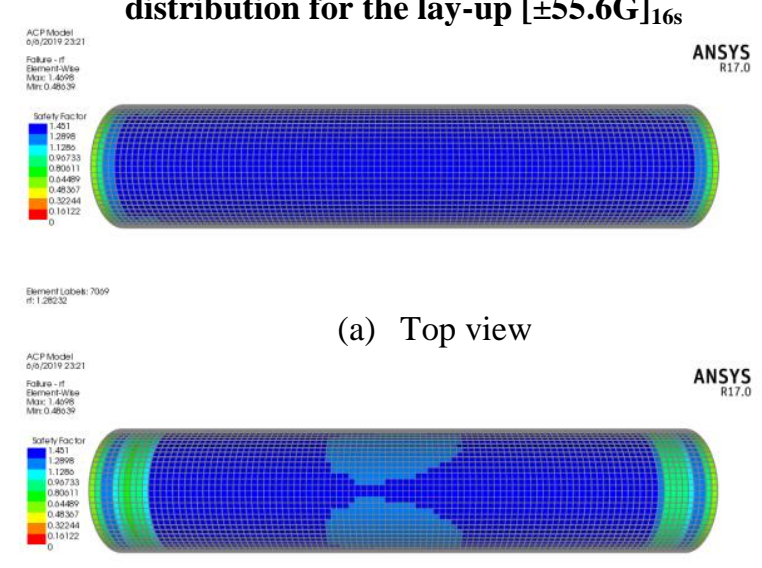

(b) Bottom view

Fig. 14 Hydro-test pressure load case: Safety factor distribution for the lay-up $[90 \mathrm{C}, \pm 0 \mathrm{G}]_{8 \mathrm{~s}}$

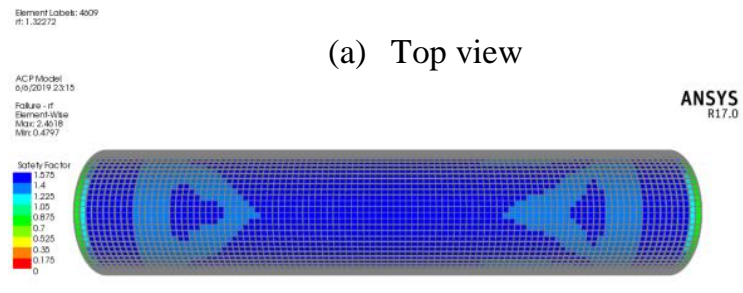

(b) Bottom view

Fig. 13 Hydro-test pressure load case: Safety factor distribution for the lay-up $[0 \mathrm{C}, \pm 90 \mathrm{G}]_{16 \mathrm{~s}}$

ANSYS
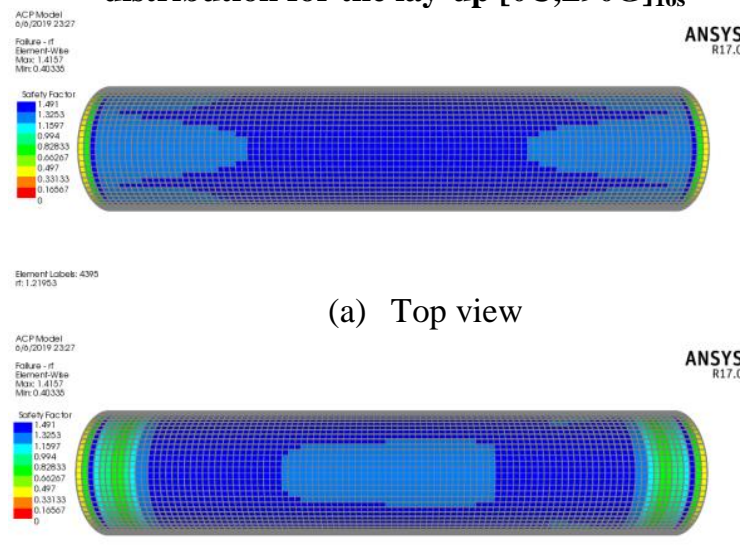

(b) Bottom view

Fig. 15 Hydro-test pressure load case: Safety factor distribution for the lay-up $[0, \pm 90 G, 90]_{9 \mathrm{~s}}$ 


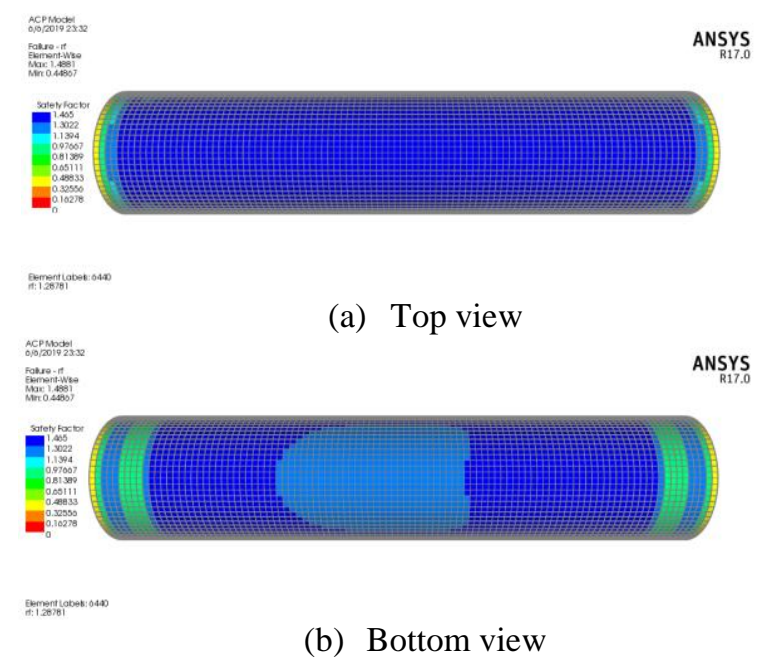

Fig. 16 Hydro-test pressure load case: Safety factor distribution for the lay-up $[90 \mathrm{C}, \pm 0 \mathrm{G}, 90 \mathrm{C}]_{7 \mathrm{~s}}$

\section{CONCLUSIONS}

Developed mathematical solution and a fair resolution parametric FEA study for three-phase separator filament-wound PV were conducted for optimal design investigation. Pure pressure load case was considered for obtaining the optimum lay-up configuration and finding the corresponding allowable wall thickness using design pressure. The effect of more realistic load cases namely; operating, and hydro-test load cases were investigated. The significant results obtained from FEM have shown agreement for both pure pressure and operating load cases. This built confidence towards constructing parametric model for the hydro-test load case. ANSYS Workbench design point parameters, and ANSYS ACP has been proven to be very effective tool for constructing a parametric models and, simulating multilayered filament-wound PVs respectively.

However, the unbalanced laminate lay-up [+54.7C,$54.7 \mathrm{G}]_{20 \mathrm{~s}}$ showed higher layers consumption when subjected to pure pressure; it represents the optimum lay-up for PVs suffering from high torsional nozzle loads may that be caused by connected piping.

All examined lay-ups showed safe design when subjected to hydro-test load case, but lay-ups with a higher content of axially oriented layers which showed distinct behavior and higher resistance to weight content. This made them the best alternative for applications with higher fluid content.

\section{REFERENCES}

[1] S. Mokhatab, W. A. Poe, and J. Y. Mak, Handbook of Natural Gas Transmission and Processing, $\quad 3^{\text {rd }}$ ed.: Gulf Professional Publishing, 2015.

[2] D. G. Pavlou, Composite Materials in Piping Applications: Design, Analysis and Optimization of Subsea and Onshore Pipelines from FRP Materials. Lancaster, Pennsylvania, USA: DEStech Publications Inc., 2013.

[3] O. M. Al-Habahbeh, and N. S. Al-Huniti, "Composite Pressure Vessels in Petroleum Industry: Status and Outlook," in Fifth Int. Conf. on Composite Science \& Technology, Sharjah, United Arab Emirates, 2005, pp. 401-406.

[4] R. Rafiee, "On the mechanical performance of glass-fibre-reinforced thermosetting-resin pipes: A review," Composite Structures, Vol. 143, pp. 151-164, 2016.

[5] K. K. Autar, Mechanics of composite materials, $2^{\text {nd }}$ ed.: CRC Press, Taylor \& Francis Group, 2006.

[6] F. C. Campbell, Manufacturing Processes for Advanced Composites. St. Louis, Missouri: Elsevier Science, 2004.

[7] J. P. B. Ramirez, D. Halm, J.C. Grandidier, S. Villalonga, and F. Nony, "700 bar type IV high pressure hydrogen storage vessel burst Simulation and experimental validation," Int. J. of Hydrogen Energy, Vol. 40, no. 38, pp. 13183-13192, 2015.

[8] J. Mackerle, "Finite elements in the analysis of pressure vessels and piping, an addendum: A bibliography (2001-2004)," Int.1 J. of Pressure Vessels and Piping, Vol. 82, pp. 571-592, 2005. 
[9] M. W. K. Rosenow, "Wind angle effects in glass fibre-reinforced polyester filament wound pipes," Composites, Vol. 15, pp. 144-152, 1984.

[10] S. T. Peters, Ed., Composite filament winding. Ohio: Materials Park, ASM Int. , 2011.

[11] A. Onder, O. Sayman, T. Dogan,and N. Tarakcioglu, "Burst failure load of composite pressure vessels," Composite Structures, Vol. 89, pp. 159-166, 2009.

[12] O. Sayman, M. E. Deniz, T. Dogan, and E. Yaylaga, "Failure pressures of composite cylinders with a plastic liner," Journal of Reinforced Plastics and Composites, Vol. 30, pp. 882-888, August 2011.

[13] L.A.L. Martins, F.L. Bastian, and T.A. Netto, "Reviewing some design issues for filament wound composite tubes," Materials and Design, Vol. 55, pp. 242-249, 2014.

[14] L. Parnas, and N. Katırc1, "Design of fiberreinforced composite pressure vessels under various loading conditions," Composite Structures, Vol. 58, pp. 83-95, 2002.

[15] M. Xia, H. Takayanagi, and K. Kemmochi, "Analysis of multi-layered filament-wound composite pipes under internal pressure," Composite Structures, Vol. 53, pp. 483-491, 2001 .

[16] L. A.L. Martins, F. L. Bastian, and T. A. Netto, "Structural and functional failure pressure of filament wound composite tubes," Materials and Design, Vol. 36, pp. 779-787, 2012.

[17] Y. Shao, A. Betti, V. Carvelli, T. Fujii , K. Okubo , O. Shibata, and Y. Fujita, "High pressure strength of carbon fibre reinforced vinylester and epoxy vessels," Composite Structures, Vol. 140, pp. 147-156, 2016.

[18] G. Perillo, N. Vedivik, and A. Echtermeyer, "Numerical and experimental investigation of impact on filament wound glass reinforced epoxy pipe," Journal of Composite Materials, Vol. 49, pp. 723-738, 2015.

[19] A.M. Kamal, T.A. El-Sayed, A.M.A. El-Butch, S.H. Farghaly, "Analytical and finite element modeling of pressure vessels for seawater reverse osmosis desalination plants," Desalination, Vol. 397, pp. 126-139, 2016.
[20] A.M. Kamal, T.A. El-Sayed, S.H. Farghaly, and A.M.A. El-Butch, "Failure pressure of composite membrane housing for SWRO desalination plants," Desalination, Vol. 411, pp. 45-58, 2017.

[21] N. Kharoua, L. Khezzar, and H. Saadawi, "CFD Modelling of a Horizontal Three-Phase Separator: A Population Balance Approach," American J. of Fluid Dynamics, Vol. 3, pp. 101$118,2013$.

[22] I. M. Daniel, and O. Ishai, Engineering mechanics of composite materials, 2nd ed. New York: Oxford University Press, 1994.

[23] S. W. Tsai, and M. Wu. Edward, "A General Theory of Strength for Anisotropic Materials," J. Composite Materials, Vol. 5, pp. 58-80, 1971.

[24] ANSYS, ANSYS Composite PrepPost User's Guide Release 17. USA: ANSYS Inc., 2016.

[25] Q. Zhang, Z.W. Wang, C.Y. Tang , D.P. Hu , P.Q. Liu, and L.Z. Xia, "Analytical solution of the thermo-mechanical stresses in a multilayered composite pressure vessel considering the influence of the closed ends," Int. J. of Pressure Vessels and Piping, Vol. 98, pp. 102-110, 2012.

[26] C. O. Horgan, and L. T. Wheeler, "SaintVenant's Principle and the Torsion of Thin Shells of Revolution," ASME Journal of Applied Mechanics, Vol. 43, pp. 663-667, 1976.

[27] C.O.Horgan, and J.G.Simmonds, "Saint-Venant end effects in composite structures," Composites Engineering, Vol. 4, pp. 279-286, 1994.

[28] ANSYS®. Release 17.0, Help system, Element Reference. ANSYS, Inc, 2017.

[29] Y. C. Fung and P. Tong, Classical and Computational Solid Mechanics: Advanced Series in Engineering Science Vol. 1. Singapore: World Scientific, 2001. 